\title{
Multifractal Detrended Cross-Correlation Analysis of the Return-Volume Relationship of Bitcoin Market
}

\author{
Wei Zhang, ${ }^{1,2}$ Pengfei Wang, ${ }^{1}$ Xiao Li, ${ }^{3}$ and Dehua Shen $\mathbb{D}^{1,2}$ \\ ${ }^{1}$ College of Management and Economics, Tianjin University, Tianjin 300072, China \\ ${ }^{2}$ China Center for Social Computing and Analytics, Tianjin University, Tianjin 300072, China \\ ${ }^{3}$ School of Finance, Nankai University, Tianjin 300350, China
}

Correspondence should be addressed to Dehua Shen; dhs@tju.edu.cn

Received 8 February 2018; Accepted 26 June 2018; Published 26 July 2018

Academic Editor: Daniela Paolotti

Copyright @ 2018 Wei Zhang et al. This is an open access article distributed under the Creative Commons Attribution License, which permits unrestricted use, distribution, and reproduction in any medium, provided the original work is properly cited.

We investigate the cross-correlations of return-volume relationship of the Bitcoin market. In particular, we select eight exchange rates whose trading volume accounts for more than 98\% market shares to synthesize Bitcoin indexes. The empirical results based on multifractal detrended cross-correlation analysis (MF-DCCA) reveal that (1) the nonlinear dependencies and power-law cross-correlations in return-volume relationship are found; (2) all cross-correlations are multifractal, and there are antipersistent behaviors of cross-correlation for $q=2$; (3) the price of small fluctuations is more persistent than that of the volume, while the volume of larger fluctuations is more antipersistent; and (4) the rolling window method shows that the cross-correlations of return-volume are antipersistent in the entire sample period.

\section{Introduction}

Since 2016, the market value and amount of cryptocurrencies based on blockchain technology have risen rapidly. At the same time, the risen price is accompanied by very violent fluctuations. For example, Bitcoin, the leading cryptocurrency, fell down more than $40 \%$ to less than $\$ 12,000$ in a month from more than $\$ 20,000$ on December 17, 2017. Despite the recent market crash, some people still attributed the rapid rise of cryptocurrencies to the bright prospect of the application of blockchain technology (https://www.ccn. com/eran-eyal-bitcoin-will-rise-above-100000/ (assessed date: February 1, 2018)). The article mentions that some blockchain backers believe Bitcoin can exceed $\$ 100,000$, while others think that the cryptocurrencies are products of speculation rather than the mediums of exchange $[1,2]$ and Bitcoin is in a bubble period [3]. In order to increase the price discovery function of Bitcoin in the financial market and meet the needs of investors in indirect cryptocurrencies, US financial firms CME and CBOE have launched Bitcoin futures, respectively. In addition, Bitcoin, to a certain extent, is an option for asset allocation and hedging [4] due to the distinctly different returns, volatility, and correlation characteristics from other assets [5]. As a form of cryptocurrency with a long history and the largest market capitalization, Bitcoin has a limit on the total amount at the beginning of the design. Besides, the correlation between price and volume is an important indicator for investigating market dynamics in classical finance. The price change denotes the market reaction to new information, while the volume change reflects investors' different understanding of new information. Studying the crosscorrelations between price and volume can reveal the speed, spread, and absorption of market information flows and the extent to which prices reflect market information. This issue has been explored in the stock market [6-9], commodity market $[10,11]$, and so on. We believe it is necessary to conduct this study in the Bitcoin market. Therefore, we fill the current research gap by investigating the return-volume relationship of the Bitcoin market.

In recent years, economic literature on Bitcoin has shown that the returns of Bitcoin run counter to the efficient market hypothesis (EMH) [12, 13]. Urquhart [14] uses several tests to test the inefficiency of Bitcoin and finds that while Bitcoin 
is not efficient, it is in the process of becoming effective. Bariviera [15] employs a dynamic detrended fluctuation analysis approach to support Urquhart's conclusion and finds that the volatility of Bitcoin has long-term memory. Besides, there is a literature on Bitcoin from the perspective of stylized facts [16-19] and relationships with other assets $[20,21]$. In line with the researches of the relationship between investor attention and asset performance [22-24], Urquhart [25] and Zhang et al. [26] explore the relation with retailed investor attention measured by Google Trends. All of these studies show that Bitcoin is different from traditional assets. Based on the scholars' findings, we study the returnvolume relationship of the Bitcoin market by employing an econophysics method.

The fractal theory proposed by Mandelbrot [27] can explain the economic phenomena that cannot be explained by the traditional efficient market hypothesis. Early fractal studies focus on rescaled range (R/S) analysis proposed by Hurst $[28,29]$ in the field of hydrology. However, Lo [30] finds that the R/S Hurst method is sensitive to short-term autocorrelation, which may lead to bias error of nonstationary time series. To overcome this shortcoming, Peng et al. [31] propose a widely used detrended fluctuation analysis that uses a long-range power law to avoid significant longrange autocorrelation false detection [32]. As a multifractal extension of DFA approach, Kantelhardt et al. [33] introduce the MF-DFA method widely used in financial markets. Podobnik and Stanley [34] extend the DFA by introducing a detrended cross-correlation analysis (DCCA) approach that can be used to study long-range cross-correlation between two nonstationary time series. On this basis, Zhou [35] proposes a new method multifractal detrended crosscorrelation analysis (MF-DCCA, MF-DXA, or MF-X-DFA), which is a combination of MF-DFA and DCCA. Then, a series of improvement methods have been proposed, such as the method of MF-PX-DFA and MF-PX-DMA [36], MF-X-DMA [37], MF-HXA [38], and MF-X-PF [39]. These increase the efficiency of some applications of the MF-DCCA method. The MF-DCCA method has been widely applied to describe the multifractal characteristics of two crosscorrelated nonstationary time series in a financial field such as the foreign exchange market $[40,41]$, the stock market [42-44], the crude oil market [45-47], carbon market $[48,49]$, and the commodity market $[50,51]$. Zhang et al. also employ MF-DCCA to examine the relationship between mass media and new media [52] and to quantify the crosscorrelation between investor sentiment proxies [53], that is, FEARS [54] and Twitter happiness sentiment [55].

Previously, the relationships between the volume and price of the stock market [6-9], agricultural commodity future markets [11], and the gold market [10] have been studied, using the multifractal detrended cross-correlation analysis method. Therefore, we conduct the MF-DCCA to investigate the cross-correlations between the return and volume of the Bitcoin market.

This paper is structured as follows. Section 2 describes the data and method of processing data. We introduce the method of MF-DCCA in Section 3. We provide empirical results and conclusions in Section 4 and Section 5, respectively.
TABLE 1: Daily volume of different exchange rates. The volume is the average daily trading volume in 2017 . Mean volume represents the average volume of the exchange rate for each market. The bold is the top 8 exchange rates which account for more than $98.35 \%$ market share.

\begin{tabular}{|c|c|c|c|}
\hline Currency & Volume & Mkt. number & Mean vol \\
\hline ARS & 4.470354 & 1 & 4.470354 \\
\hline AUD & 461.0146 & 2 & 230.5073 \\
\hline$B R L$ & 914.7376 & 3 & 304.9125 \\
\hline CAD & 107.9026 & 2 & 53.95132 \\
\hline $\mathrm{CHF}$ & 2.974501 & 1 & 2.974501 \\
\hline CLP & 1.101236 & 1 & 1.101236 \\
\hline $\mathrm{CZK}$ & 3.483695 & 2 & 1.741847 \\
\hline DKK & 1.672666 & 1 & 1.672666 \\
\hline EUR & 18751.29 & 13 & 1442.407 \\
\hline$G B P$ & 2357.178 & 4 & 589.2945 \\
\hline HKD & 12.3385 & 1 & 12.3385 \\
\hline IDR & 715.4489 & 2 & 357.7245 \\
\hline ILS & 34.51753 & 2 & 17.25877 \\
\hline INR & 29.57731 & 1 & 29.57731 \\
\hline$J P Y$ & 72848.44 & 6 & 12141.41 \\
\hline$K R W$ & 5889.262 & 1 & 5889.262 \\
\hline MXN & 8.559472 & 1 & 8.559472 \\
\hline MYR & 190.0112 & 1 & 190.0112 \\
\hline NGN & 70.77995 & 1 & 70.77995 \\
\hline NOK & 17.85582 & 1 & 17.85582 \\
\hline NZD & 21.38022 & 1 & 21.38022 \\
\hline PKR & 14.49338 & 1 & 14.49338 \\
\hline PLN & 1422.03 & 5 & 284.406 \\
\hline$R U B$ & 2046.448 & 4 & 511.6121 \\
\hline SEK & 29.7208 & 2 & 14.8604 \\
\hline SGD & 76.45168 & 3 & 25.48389 \\
\hline SLL & 51.89407 & 1 & 51.89407 \\
\hline THB & 24.94223 & 1 & 24.94223 \\
\hline USD & 47526.69 & 16 & 2970.418 \\
\hline VEF & 64.25689 & 2 & 32.12844 \\
\hline VND & 12.52992 & 2 & 6.264962 \\
\hline ZAR & 583.2546 & 2 & 291.6273 \\
\hline
\end{tabular}

\section{Data Description}

The data in this paper is from https://bitcoincharts.com/, a website that provides Bitcoin financial and technical data. The Bitcoincharts website collects market data from various Bitcoin markets around the world and divides them into active and inactive markets. The symbol provided by the website, such as bitstampUSD, consists of two parts; the lowercase part is the trading market and the uppercase part is the exchange rate. In the active section, the website has 90 pairs (market and exchange rate), of which bcEUR, bitmarketEUR, and bitmarketPLN are not provided with complete data (https://bitcoincharts.com/markets/list/). Therefore, we choose 87 pairs out of 90 pairs. 


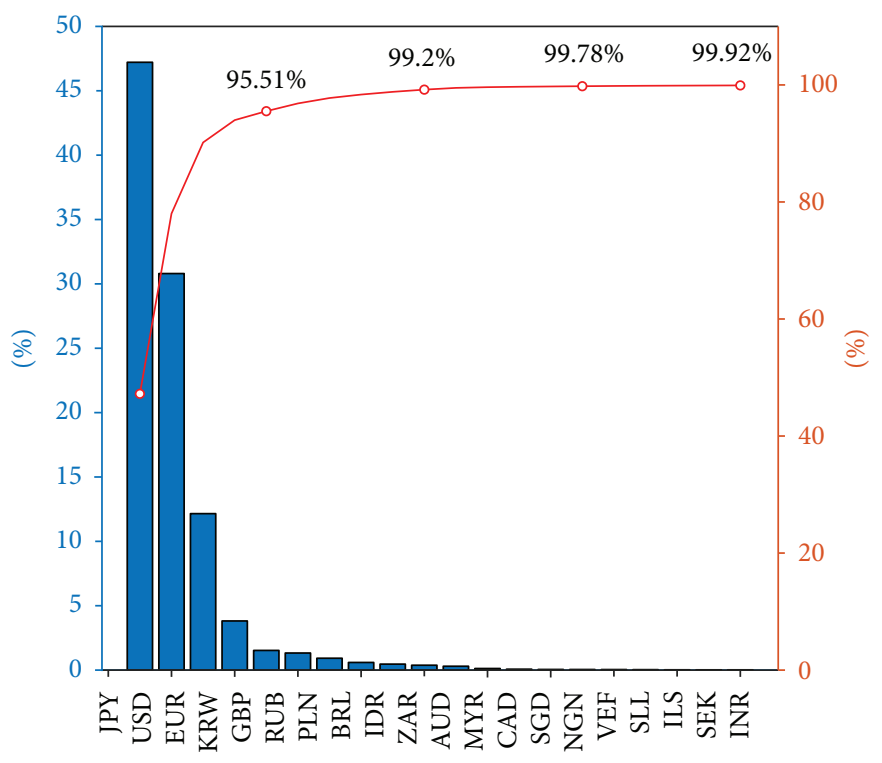

FIGURE 1: Share of each exchange rate and accumulative share.

We rank the daily trading volume of 2017 in different exchange rates and find that the top 8 exchange rates account for more than $98 \%$. The top 8 exchange rates' symbols BRL, EUR, GBP, JPY, KRW, PLN, RUB, and USD denote Brazilian real, euro, British pound, Japanese yen, Korean won, Polish zloty and US dollars. Table 1 reports the volume of each currency in 2017 and the average volume of each market. And the proportion of each exchange rate and cumulative proportions are shown in Figure 1. From Table 2, we can see that the oldest market in each exchange rate is not the largest volume. Likewise, the market with the largest volume does not have the longest span of time. And since different markets in the first eight exchange rates have different starting dates for trading and the average daily trading volume is different, we use the raw data for each market to calculate the volume-weighted average composite price index in order to avoid market bias. In the synthesis procedure, we get the weighted sum of the closing price that is denominated in different exchange rates to get the index price: price $_{t}=$

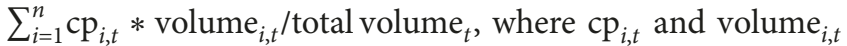
denote the closing price and trading volume of the $i$ th symbol at $t$ day, and total volume ${ }_{t}=\sum_{i=1}^{n}$ volume $_{i, t}$. The volume of the composite index is the sum of symbols denominated in the same currency. Table 2 shows the basic information for each of the first eight exchange rates, including the start date and the average daily volume for 2017. And Table 3 shows the start date and end date of the synthetic composite Bitcoin price index. USD, EUR, and BRL have the longest span of time, with more than 2200 data points.

The daily returns and volume change are defined:

$$
\begin{aligned}
& r_{t}=\ln \left(\frac{\text { price }_{t}}{\text { price }_{t-1}}\right), \\
& v_{t}=\ln \left(\frac{\text { volume }_{t}}{\text { volume }_{t-1}}\right),
\end{aligned}
$$

where price $_{t}$ and volume $e_{t}$ are the closing price and trading volume on trading day $t$, respectively. The daily return data for the entire period of the Bitcoin market is given in Figure 2, indicating the presence of volatility clustering. However, even though the eight charts in Figure 2 are all about Bitcoin returns, the difference between different exchange rates is significant. For BRL, EUR, and USD that have similar time spans, extrema and degree of volatility clustering significantly vary. Similarly, fluctuations in the trading volume of BRL, RUB, PLN, and USD show a declining trend, while other exchange rates are relatively stable, and GBP may even rise (see Figure 3 ). This also proves that the global Bitcoin market is not fully synchronized, so it is necessary to study the different markets of Bitcoin. Table 4 shows the statistical properties of the Bitcoin market. In panel A, we can see that the BRL and RUB indicators are significantly different from other exchange rates, with greater standard deviation, kurtosis, and J-B statistics, which means the BRL and RUB markets are more volatile. The Jarque-Bera test rejects the null hypothesis that time series obeys normal distribution at a significance level of $1 \%$. The kurtosis of returns and volume change is greater than 3 , indicating that the time series is leptokurtic. Both the return and volume change series are not normal distribution.

\section{Methodology}

Zhou [35] introduces the MF-DCCA method to analyze the cross-correlation of two nonstationary series. Let us consider two time series $\left\{x_{i}\right\}$ and $\left\{y_{i}\right\}$ of the same length $N$, where $i=1,2, \ldots, N$. Then, we determine the profile: $X_{i}=$ $\sum_{k=1}^{i}\left(x_{k}-\bar{x}\right), \quad Y_{i}=\sum_{k=1}^{i}\left(y_{k}-\bar{y}\right), i=1,2, \ldots, N$, where $\bar{x}$ and $\bar{y}$ are the mean values of the time series $\left\{x_{i}\right\}$ and $\left\{y_{i}\right\}$.

The integrated time series $X_{i}$ and $Y_{i}$ have eliminated the trend. Then, we divide the two profiles into $N_{s} \equiv$ int $(N / s)$ nonoverlapping segments of equal length $s$, respectively. If length $N$ cannot be divisible by scale $s$, then a short part will 
TABLE 2: Basic information for each market of top 8 exchange rates.

\begin{tabular}{|c|c|c|c|}
\hline Currency & Market & Start date & Daily volume \\
\hline BRL & Foxbit & 20141211 & 532.92 \\
\hline BRL & Localbtc & 20130318 & 15.67 \\
\hline$B R L$ & Mrcd & 20110728 & 366.15 \\
\hline EUR & Abucoins & 20170921 & 10.02 \\
\hline EUR & Bitbay & 20150317 & 22.66 \\
\hline$E U R$ & Btcde & 20110826 & 845.45 \\
\hline EUR & Cex & 20140926 & 152.75 \\
\hline EUR & Coinbase & 20150423 & 1961.44 \\
\hline EUR & Coinfalcon & 20171013 & 157.68 \\
\hline EUR & Coinsbank & 20170703 & 1563.57 \\
\hline EUR & Itbit & 20131117 & 142.06 \\
\hline EUR & Kraken & 20140108 & 11132.42 \\
\hline EUR & Localbtc & 20130312 & 95.46 \\
\hline EUR & Rock & 20111109 & 267.31 \\
\hline EUR & Wex & 20171017 & 158.55 \\
\hline EUR & Zyado & 20140424 & 2241.92 \\
\hline GBP & Coinbase & 20150421 & 339.00 \\
\hline GBP & Coinfloor & 20140329 & 790.40 \\
\hline GBP & Coinsbank & 20170703 & 951.48 \\
\hline$G B P$ & Localbtc & 20130311 & 276.29 \\
\hline JPY & Bitflyer & 20170704 & 18769.10 \\
\hline$J P Y$ & Btcbox & 20140409 & 4251.26 \\
\hline JPY & Coincheck & 20141031 & 32811.68 \\
\hline JPY & Fisco & 20171018 & 9707.05 \\
\hline JPY & Kraken & 20170611 & 69.24 \\
\hline JPY & Zaif & 20170627 & 7240.11 \\
\hline$K R W$ & Korbit & 20130903 & 5889.26 \\
\hline PLN & Abucoins & 20170918 & 60.35 \\
\hline PLN & Bitbay & 20140329 & 1306.06 \\
\hline PLN & Bitmaszyna & 20170804 & 7.56 \\
\hline$P L N$ & Localbtc & 20130624 & 2.60 \\
\hline PLN & Nevbit & 20170412 & 45.45 \\
\hline RUB & Cex & 20150806 & 2.71 \\
\hline RUB & Coinsbank & 20170629 & 1331.30 \\
\hline$R U B$ & Localbtc & 20130328 & 497.04 \\
\hline RUB & Wex & 20171017 & 215.39 \\
\hline USD & Abucoins & 20170921 & 9.66 \\
\hline USD & Bitbay & 20140516 & 14.43 \\
\hline USD & Bitkonan & 20130702 & 2.18 \\
\hline USD & Bitstamp & 20110913 & 12873.29 \\
\hline USD & Btcalpha & 20161101 & 147.61 \\
\hline USD & Btcc & 20161102 & 87.78 \\
\hline USD & Cex & 20140718 & 1170.66 \\
\hline USD & Coinbase & 20141201 & 15057.84 \\
\hline USD & Coinsbank & 20170703 & 1701.17 \\
\hline USD & Getbtc & 20170616 & 851.68 \\
\hline USD & Itbit & 20130825 & 2785.99 \\
\hline USD & Kraken & 20140107 & 5048.12 \\
\hline
\end{tabular}

TABle 2: Continued.

\begin{tabular}{lccc}
\hline Currency & Market & Start date & Daily volume \\
\hline USD & Lake & 20140301 & 4872.08 \\
USD & Localbtc & 20130311 & 529.29 \\
USD & Okcoin & 20170807 & 559.40 \\
USD & Wex & 20170919 & 1815.51 \\
\hline
\end{tabular}

TABLE 3: Start date and end date of top 8 exchange rates.

\begin{tabular}{llll}
\hline Currency & Start date & End date & Obs. \\
\hline BRL & 20110728 & 20180118 & 2242 \\
EUR & 20110826 & 20180118 & 2336 \\
GBP & 20130311 & 20180118 & 1775 \\
JPY & 20140409 & 20180118 & 1380 \\
KRW & 20130903 & 20180118 & 1590 \\
PLN & 20130624 & 20180118 & 1565 \\
RUB & 20130328 & 20180118 & 1578 \\
USD & 20110913 & 20180118 & 2302 \\
\hline
\end{tabular}

be kept at the end of the profile. In order not to neglect the short part, we repeat the same procedure starting from the end of the profile, so $2 N_{s}$ segments are obtained.

The local trend of the series $\tilde{X}_{v}(i)$ and $\tilde{Y}_{v}(i)$ is determined for each segment $v ; \tilde{X}_{v}(i)=\tilde{a}_{k} i^{m}+\cdots+\tilde{a}_{1} i+\tilde{a}_{0}$ and $\tilde{Y}_{v}(i)=\tilde{b}_{k} i^{m}+\cdots+\tilde{b}_{1} i+\tilde{b}_{0}$, where $i=1,2, \ldots, s, \quad v=$ $1,2, \ldots, 2 N_{s}$, and $m=1,2, \ldots$. Then, we calculate the polynomial fit of each segment $v$ and obtain the detrended covariance

$$
\begin{aligned}
F^{2}(s, v)= & \frac{1}{s} \sum_{j=1}^{s}\left[X((v-1) s+j)-\tilde{X}_{v}(i)\right] \\
\cdot & {\left[Y((v-1) s+j)-\tilde{Y}_{v}(i)\right] }
\end{aligned}
$$

for $v=1,2, \ldots, N_{s}$, and

$$
\begin{aligned}
F^{2}(s, v)= & \frac{1}{s} \sum_{j=1}^{s}\left[X\left(N-\left(v-N_{s}\right) s+j\right)-\tilde{X}_{v}(i)\right] \\
& \cdot\left[Y\left(N-\left(v-N_{s}\right) s+j\right)-\tilde{Y}_{v}(i)\right]
\end{aligned}
$$

for $v=N_{s}+1, N_{s}+2, \ldots, 2 N_{s}$, where $\tilde{X}_{v}(i)$ and $\tilde{Y}_{v}(i)$ are the local trends.

The $q$-order fluctuation function is obtained by averaging all the segments

$$
F_{q}(s)=\left\{\frac{1}{2 N_{s}} \sum_{\lambda=1}^{2 N_{s}} F^{2}(s, v)^{q / 2}\right\}^{1 / q}
$$

And when $q=0$, the equation is $F_{0}(s)=\exp \left\{1 / 4 N_{s} \sum_{\lambda=1}^{2 N_{s}}\right.$ $\left.\ln \left[F^{2}(s, v)\right]\right\}$.

The scale behavior of the fluctuation function is analyzed by observing the logarithmic plots of $F_{q}(s)$ versus $s$. If the two 


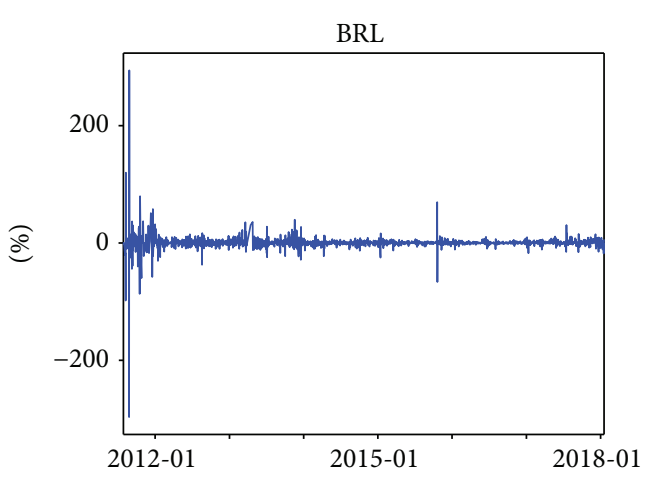

(a)

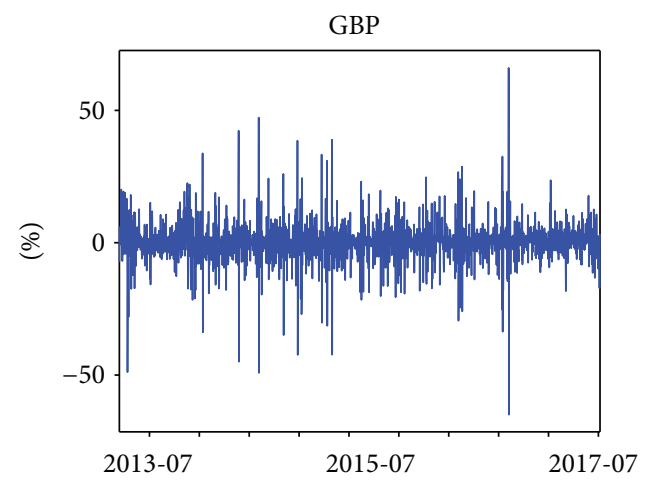

(c)

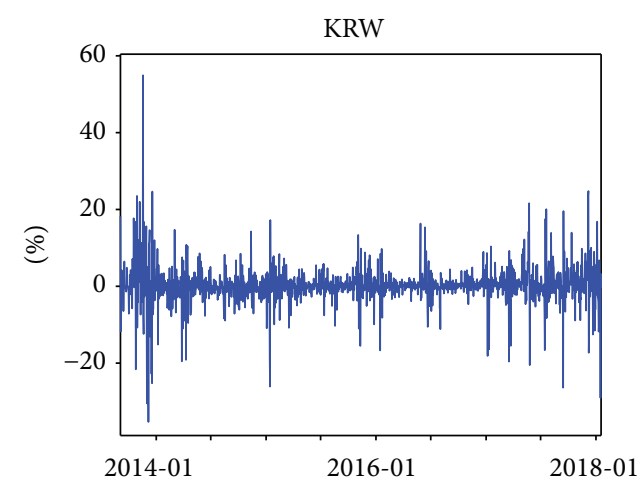

(e)

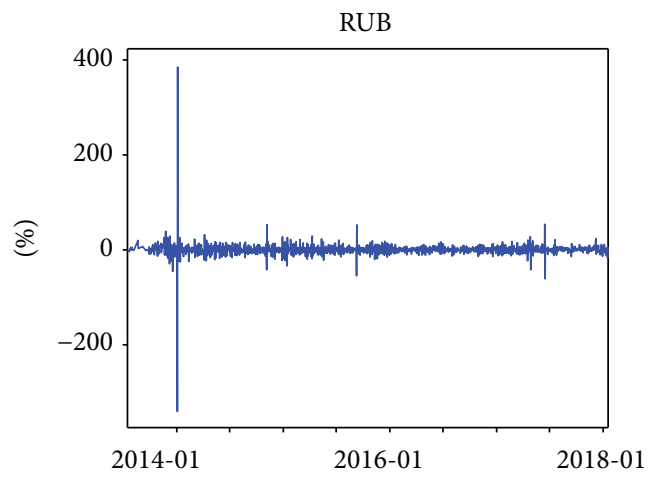

(g)

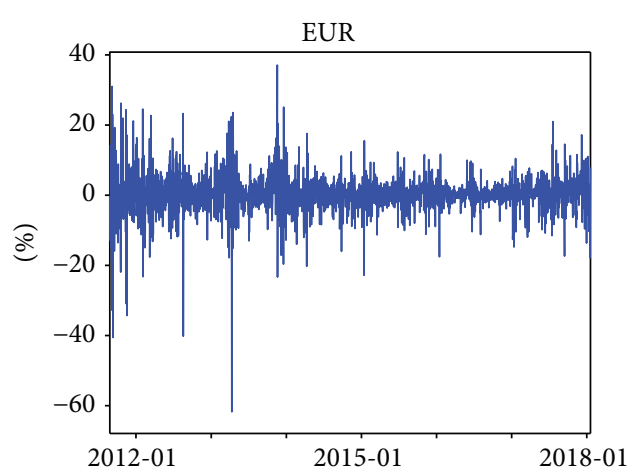

(b)

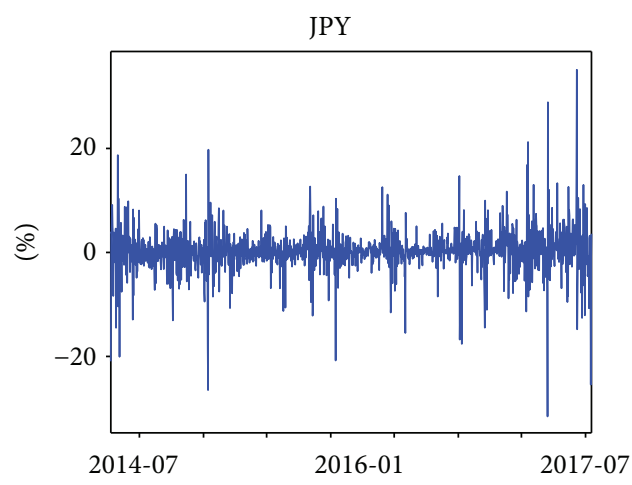

(d)

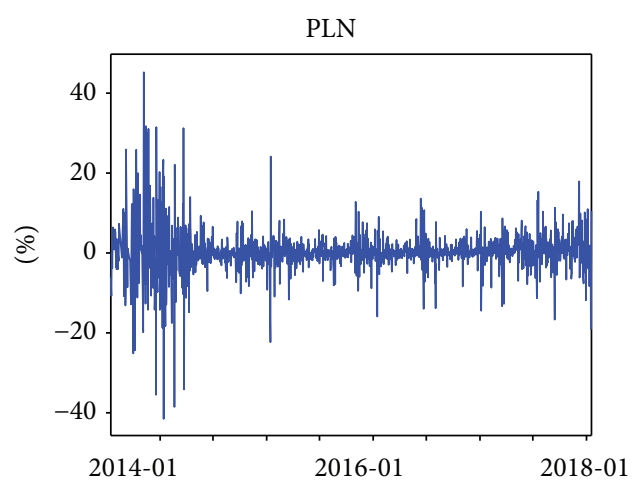

(f)

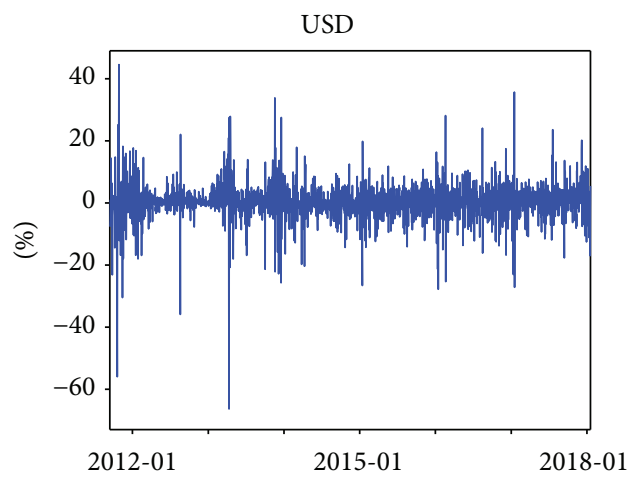

(h)

FIGURE 2: Returns of the Bitcoin market. 
BRL

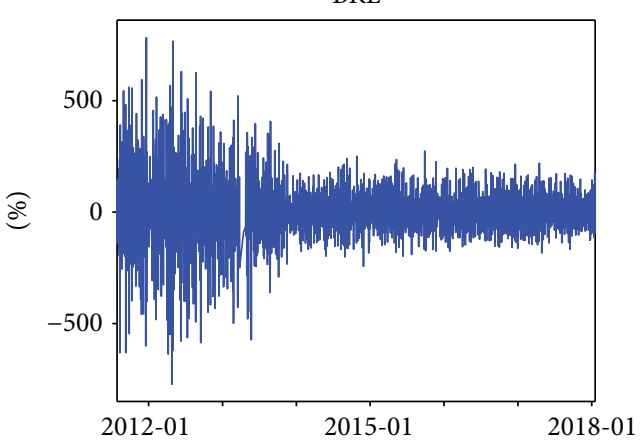

(a)

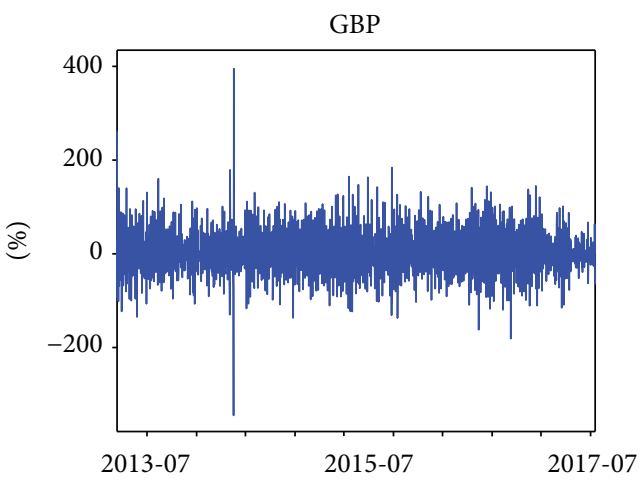

(c)

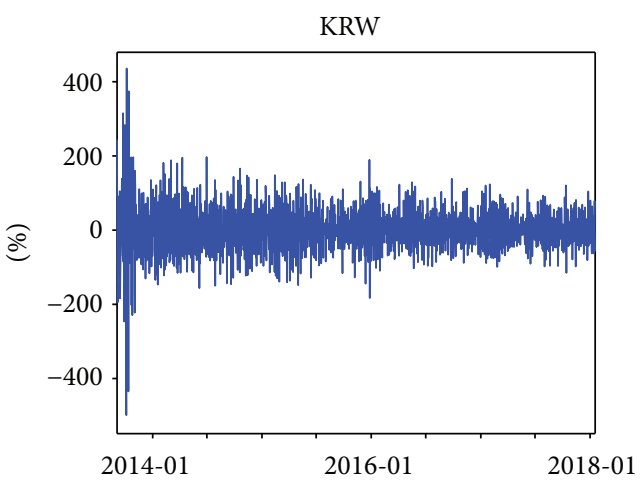

(e)

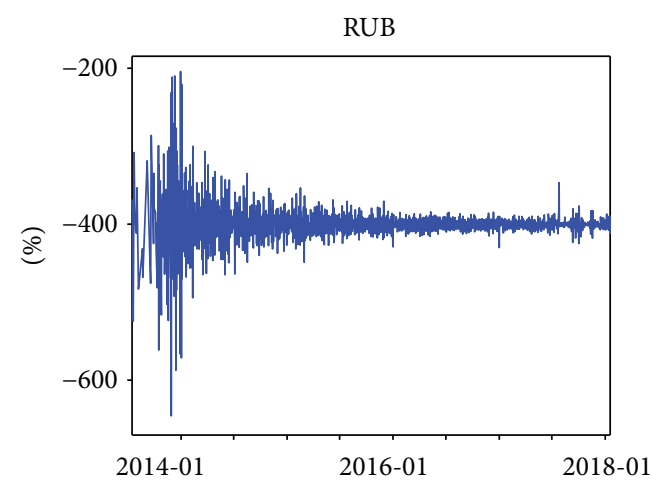

(g)

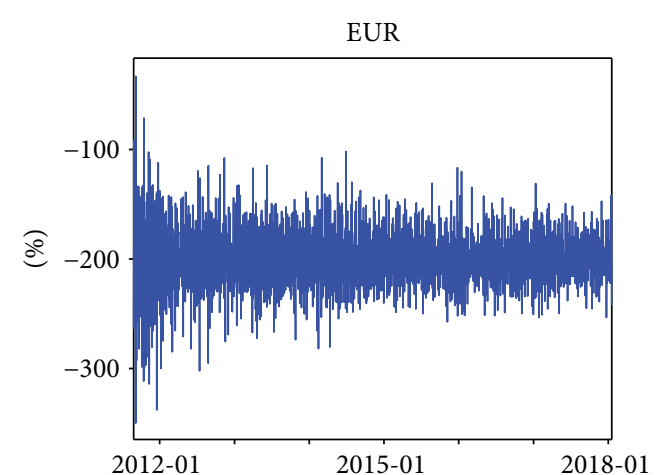

(b)

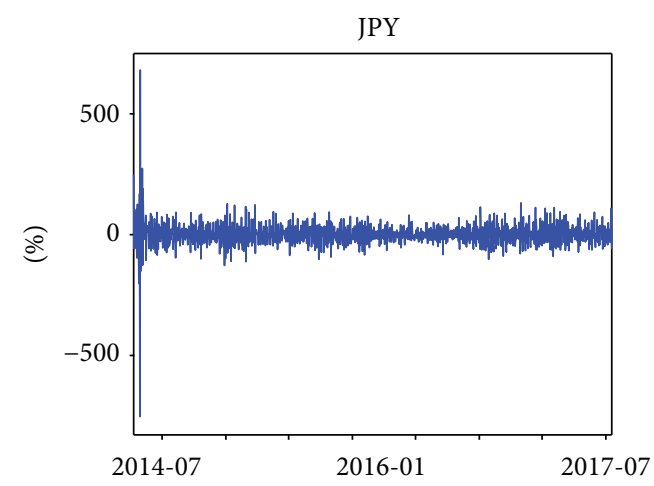

(d)

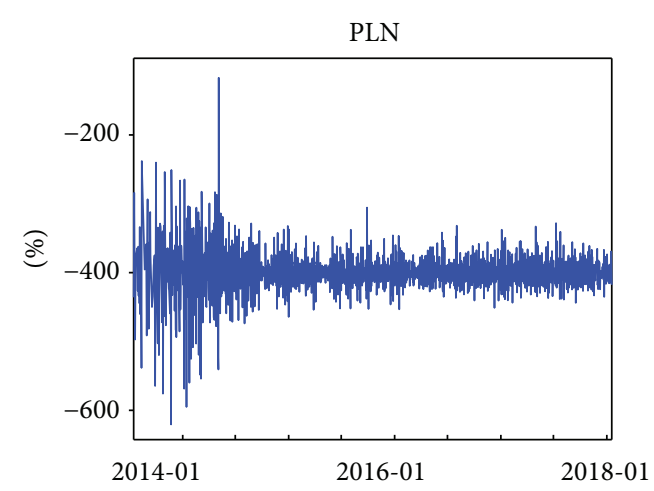

(f)

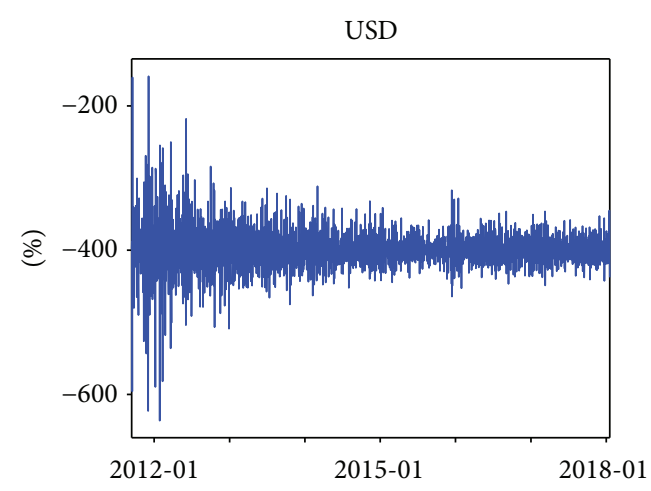

(h)

FIgURE 3: Volume change of the Bitcoin market. 
TABle 4: Descriptive statistics for the Bitcoin market time series.

(a) Statistical properties of price change

\begin{tabular}{lccccccccc}
\hline Currency & Mean & Median & Std & Max. & Min. & Skewness & Kurtosis & Jarque-Bera & Obs. \\
\hline BRL & 0.0033 & 0.0012 & 0.1172 & 2.9429 & -2.9673 & -0.0678 & 373.9244 & $12846991.37^{* * *}$ & 2241 \\
EUR & 0.0031 & 0.0029 & 0.0565 & 0.3709 & -0.6175 & -0.7343 & 15.9916 & $16630.86^{* * *}$ & 2335 \\
GBP & 0.0031 & 0.0039 & 0.0804 & 0.6603 & -0.6496 & -0.2600 & 13.7927 & $8629.91^{* * *}$ & 1774 \\
JPY & 0.0024 & 0.0020 & 0.0426 & 0.3514 & -0.3154 & -0.2271 & 15.0605 & $8369.46^{* * *}$ & 1379 \\
KRW & 0.0029 & 0.0012 & 0.0492 & 0.5494 & -0.3532 & 0.3396 & 21.1442 & $21827.20^{* * *}$ & 1589 \\
PLN & 0.0030 & 0.0021 & 0.0535 & 0.4523 & -0.4154 & 0.1621 & 18.3915 & $15434.84^{* * *}$ & 1563 \\
RUB & 0.0036 & 0.0010 & 0.1558 & 3.8493 & -3.4028 & 2.8241 & 382.8340 & $9482091.38^{* * *}$ & 1577 \\
USD & 0.0033 & 0.0038 & 0.0591 & 0.4455 & -0.6636 & -1.0286 & 19.8176 & $27522.38^{* * *}$ & 2301 \\
\hline
\end{tabular}

(b) Statistical properties of volume change

\begin{tabular}{lccccccccc}
\hline Currency & Mean & Median & Std & Max. & Min. & Skewness & Kurtosis & Jarque-Bera & Obs. \\
\hline BRL & 0.0027 & -0.0297 & 1.3674 & 7.8313 & -7.7223 & 0.0621 & 8.1312 & $2459.95^{* * *}$ & 2241 \\
EUR & 0.0035 & -0.0080 & 0.5457 & 3.3349 & -2.9957 & 0.0697 & 5.3577 & $542.69^{* * *}$ & 2335 \\
GBP & 0.0026 & -0.0277 & 0.4949 & 3.9505 & -3.4478 & 0.4587 & 7.3116 & $1436.31^{* * *}$ & 1774 \\
JPY & 0.0088 & -0.0122 & 0.4832 & 6.8152 & -7.5347 & -0.4213 & 74.9053 & $297122.05^{* * *}$ & 1379 \\
KRW & 0.0059 & -0.0164 & 0.6397 & 4.3582 & -4.9870 & 0.0017 & 9.3632 & $2680.84^{* * *}$ & 1589 \\
PLN & 0.0057 & -0.0289 & 0.8054 & 7.0761 & -5.5133 & -0.0655 & 13.8337 & $7644.75^{* * *}$ & 1563 \\
RUB & 0.0048 & 0.0060 & 0.6393 & 4.8952 & -6.1465 & 0.0260 & 24.8634 & $31409.28^{* * *}$ & 1577 \\
USD & 0.0030 & -0.0288 & 0.7592 & 6.0276 & -5.9090 & 0.1337 & 13.5211 & $10619.66^{* * *}$ & 2301 \\
\hline
\end{tabular}

${ }^{* * *}$ Denotes statistical significance at $1 \%$ level.

time series are cross-correlated, we get the following power-law relationship:

$$
F_{q}(s) \propto s^{H_{x y}(q)}
$$

Equation (5) can be rewritten as

$$
\log F_{q}(s)=H_{x y}(q) \cdot \log s+\log C
$$

In the empirical section, we will draw logarithmic graphs according to (6). The cross-correlation exponent $H_{x y}(q)$ in (5) can describe the power-law relationship between two nonstationary time series. In particular, MF-DCCA is identical to MF-DFA if time series $x$ is the same as $y$. If $q=2$, the cross-correlation exponent $H_{x y}(q)$ is equivalent to the generalized Hurst exponent.

According to Shadkhoo and Jafari [56], the similarity between the classical multifractal exponent $\tau_{x y}(q)$ and $q$ can be given by

$$
\tau_{x y}(q)=q H_{x y}(q)-1
$$

If $\tau_{x y}(q)$ is a linear function of $q$, the cross-correlation of the two correlated series is monofractal; otherwise, it is multifractal. Through Legendre conversion, we can get the following relationship:

$$
\begin{aligned}
& \alpha_{x y}(q)=H_{x y}(q)+H_{x y}^{\prime}(q), \\
& f_{x y}(\alpha)=q\left[\alpha_{x y}-H_{x y}(q)\right]+1
\end{aligned}
$$

Multifractal intensity can be estimated by the width of the multifractal spectrum, which is given by the following equation:

$$
\Delta \alpha=\alpha_{\max }-\alpha_{\min } .
$$

Based on Podobnik and Stanley [34], when $q=2$, for two fractionally autoregressive integral moving average (ARFIMA) processes that share the same random noise, the cross-correlation exponent is approximately identical to the mean value of the individual Hurst exponents. Zhou [35] also observes that for the two time series constructed by the binomial measure of the $p$-model, there is the following equation:

$$
\mathrm{H}_{x y}(q)=\frac{\left[\mathrm{H}_{x x}(q)+\mathrm{H}_{y y}(q)\right]}{2} .
$$

\section{Empirical Results}

4.1. Cross-Correlation Test. In order to study the correlation between the volume and price of Bitcoin markets, we employ 


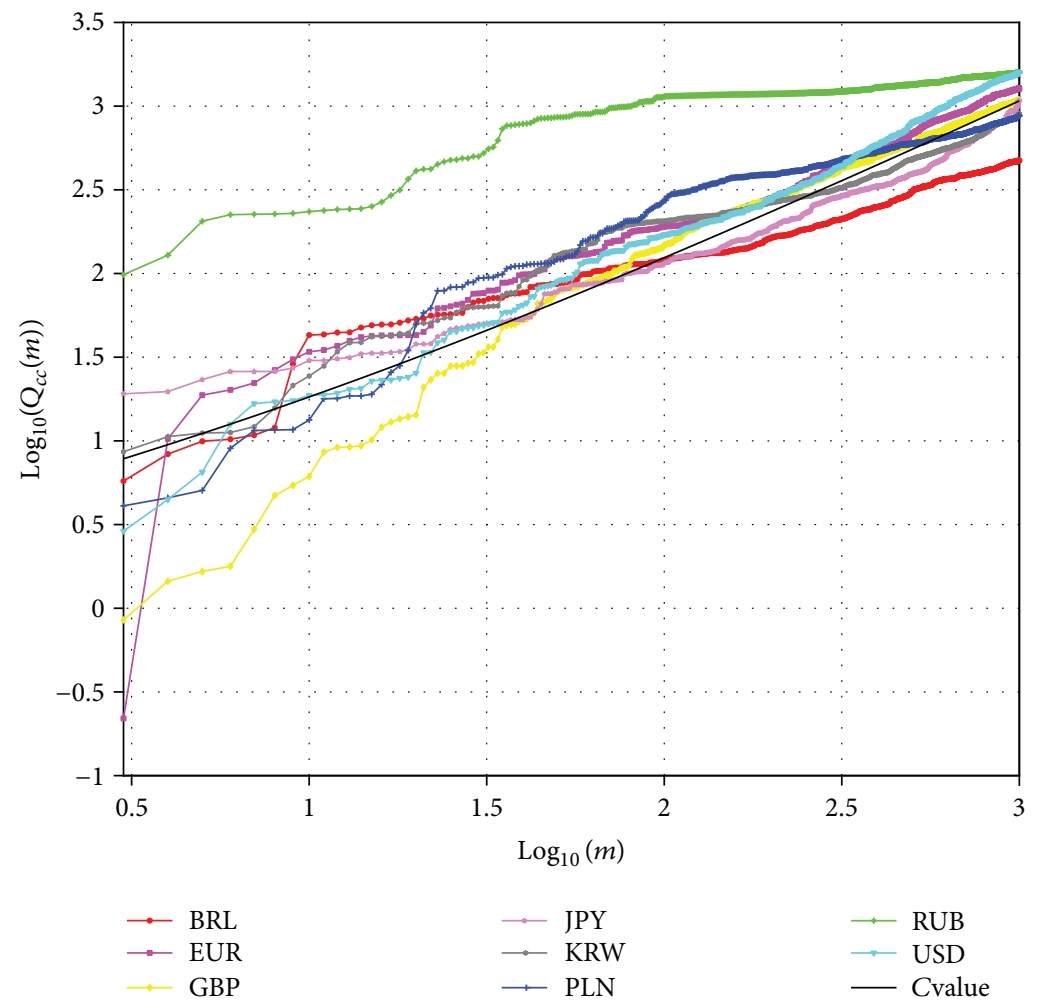

Figure 4: The cross-correlation statistics between price and volume.

the cross-correlation test developed by Podobnik et al. [57]. This is a qualitative way of testing the level of significance of cross-correlation between any two nonstationary time series.

For the two time series $\left\{x_{i}\right\}$ and $\left\{y_{i}\right\}$ with the equal length $N$, the test statistic is defined as

$$
Q_{c c}(m)=N^{2} \sum_{i=1}^{m} \frac{X_{i}^{2}}{N-i},
$$

where $X_{i}^{2}$ is the cross-correlation function

$$
X_{i}=\frac{\sum_{k=i+1}^{N} x_{k} y_{k-i}}{\sqrt{\sum_{k=1}^{N} x_{k}^{2} \sum_{k=1}^{N} y_{k}^{2}}} .
$$

The test statistic $Q_{c c}(m)$ is approximately $\chi^{2}(m)$ distributed with $m$ degrees of freedom. We use $Q_{c c}$ statistics to test the null hypothesis that the first $m$ has a nonzero correlation coefficient. Therefore, if the value of $Q_{c c}$ is larger than the critical value of $\chi^{2}(m)$, the cross-correlation between the two time series is significant.

In Figure 4, the black line is the critical value of $\chi^{2}(m)$ at $5 \%$ significant level, and the degrees of freedom vary from 1 to 1000 . The cross-correlation statistics show that the value of $Q_{c c}(m)$ deviates from the critical value $\chi^{2}(m)$ at $5 \%$ significant level, indicating that the two time series have nonlinear cross-correlation regardless of $m$ changes. Thus, we can reject the null hypothesis of no cross-correlations.
Besides, we can clearly see that the green line representing the RUB deviates from the other lines. In combination with Table 2 and Figures 2 and 3, the RUB does show different characteristics. We speculate that this is related to the proposed banning of Bitcoin by the Russian Ministry of Finance in August 2014 [58].

4.2. Multifractal Detrended Cross-Correlation Analysis. The cross-correlation test in Section 4.1 has qualitatively described the existence of nonlinear cross-correlations between the time series of price and volume. To quantify the cross-correlation, we employ the MF-DCCA method to quantitatively estimate the cross-correlation exponent in this section. And the scale $q$ is set from -10 to 10 in this paper.

According to (2), (3), (4), (5), and (6), the log-log plots of fluctuation function $F_{x y q}(s)$ versus time scale $s$ of the returnvolume in the Bitcoin market are shown in Figure 5. We find that, although the increasing rates of the fluctuation function $F_{x y q}(s)$ of eight exchange rates vary, they all increase linearly with the scale $s$. Therefore, there exist power-law behavior and long-range cross-correlation of price and volume time series in the Bitcoin market.

The legends $H_{x x}-p, H_{y y}-p$, and $H_{x y}-p v$ in Figure 6 denote the Hurst exponent of price, volume, and bivariate. The average scaling exponents are the black lines with asterisk in Figure 6. The general Hurst exponents $H_{x x}(q)$ and $H_{y y}(q)$ are calculated by using MF-DFA. MF-DCCA is identical to DCCA for $q=2$. And the bivariate Hurst 


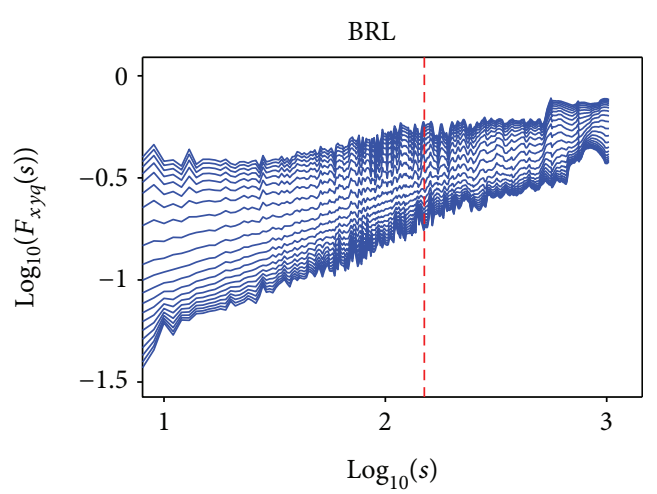

(a)

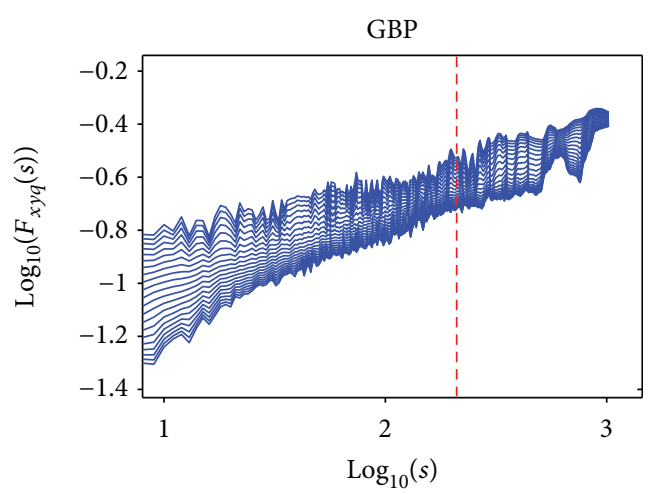

(c)

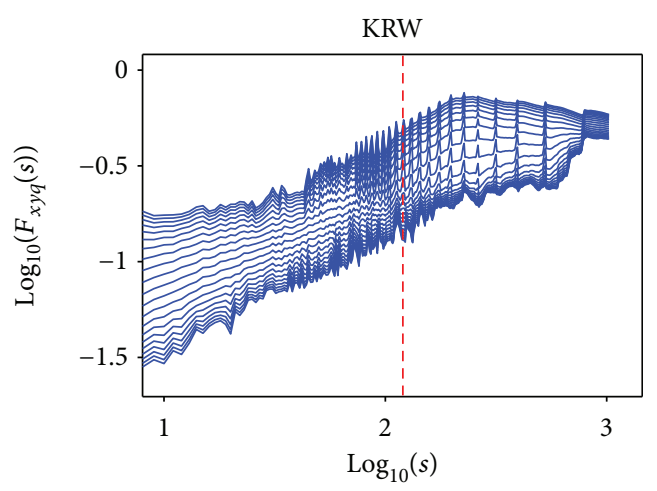

(e)

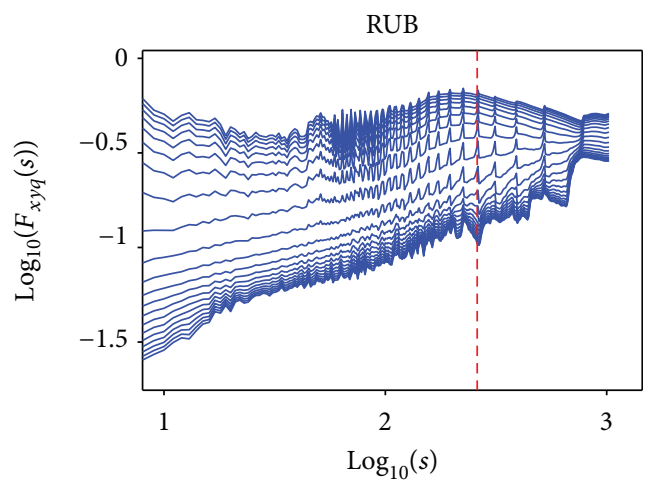

(g)

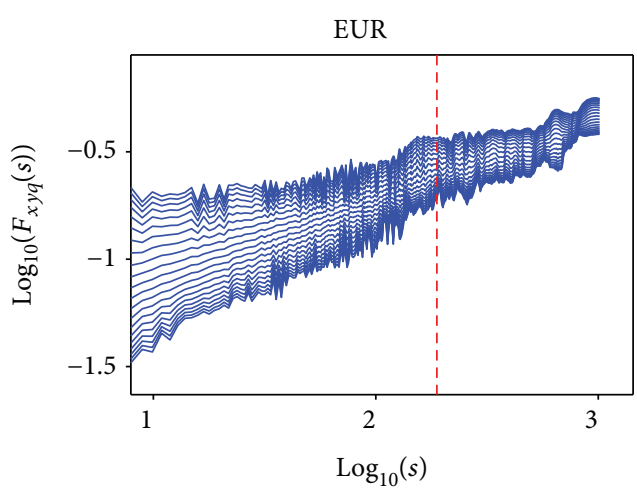

(b)

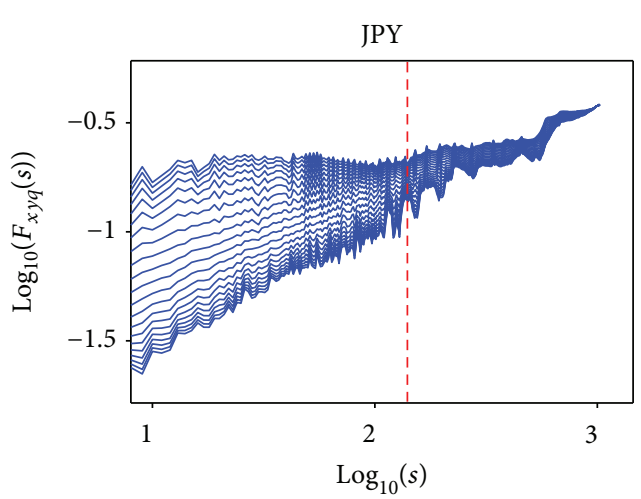

(d)

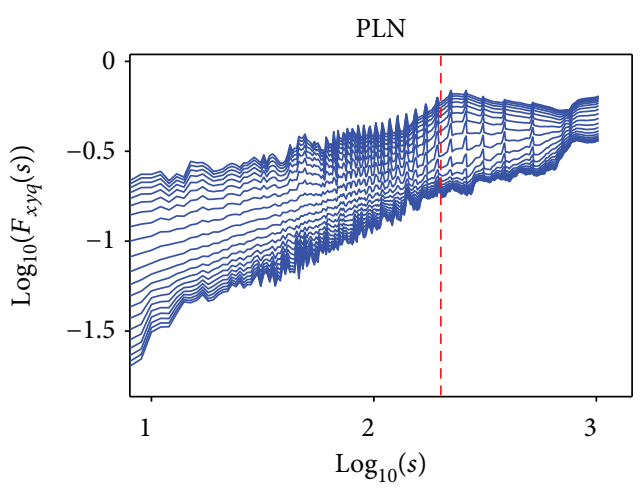

(f)

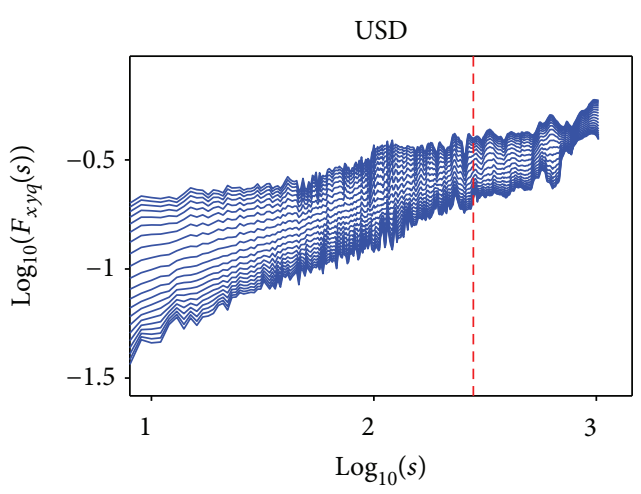

(h)

FIGURE 5: The $\log -\log$ plots of fluctuation function $F_{x y q}(q)$ versus $s$ for price-volume series when the polynomial order $m=1$. 
BRL

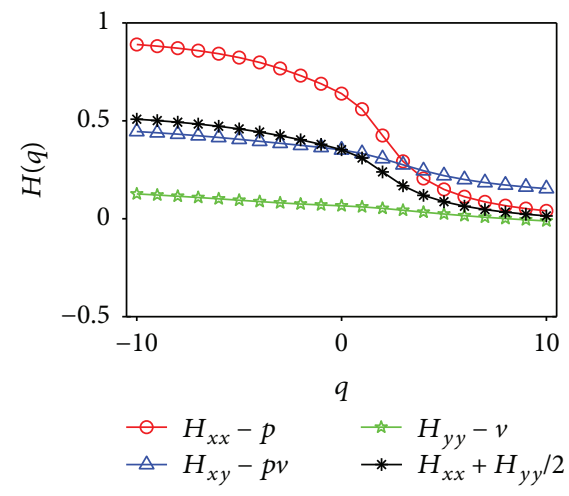

(a)

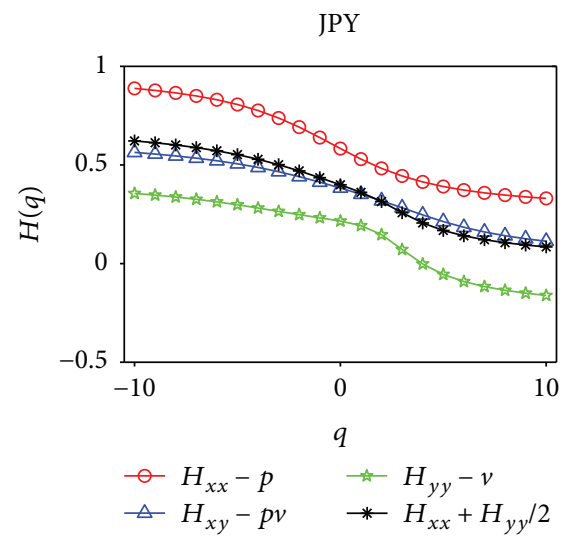

(d)
EUR

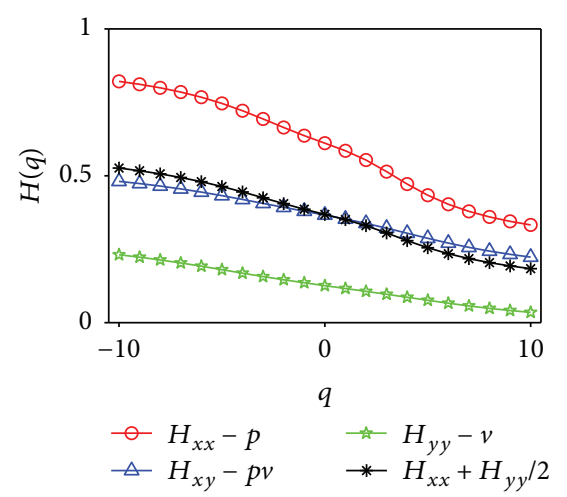

(b)

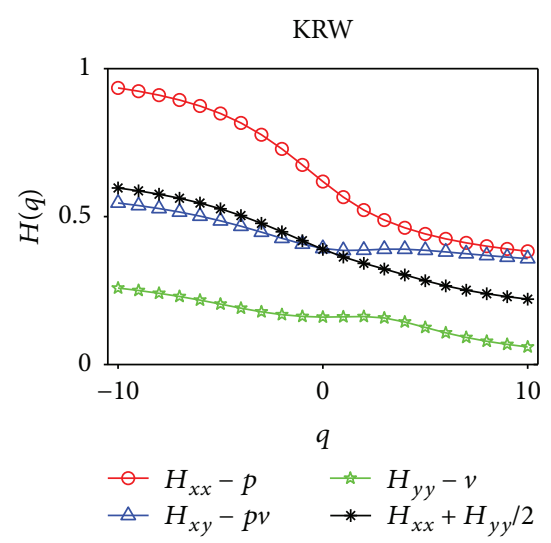

(e)
GBP

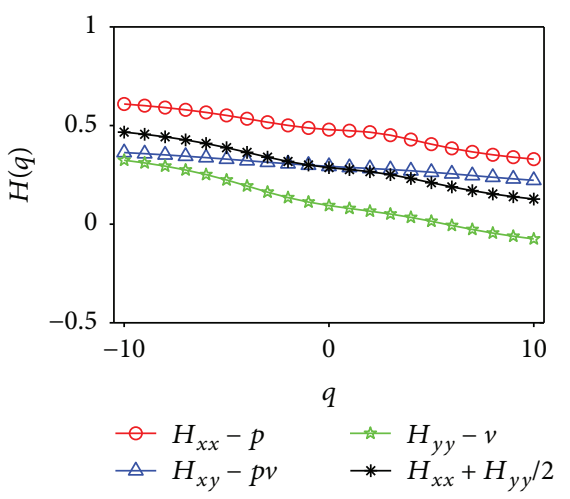

(c)

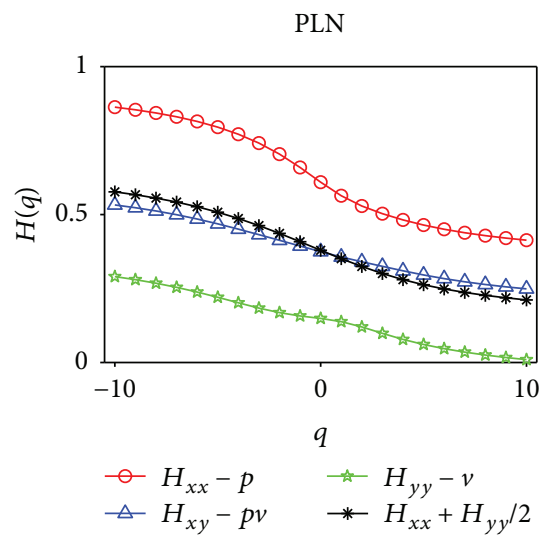

(f)
RUB

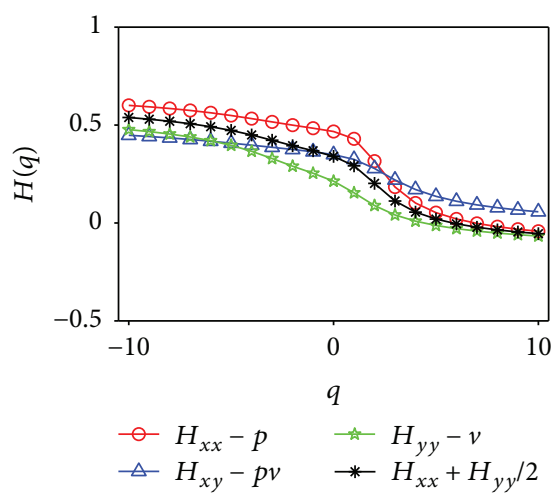

(g)

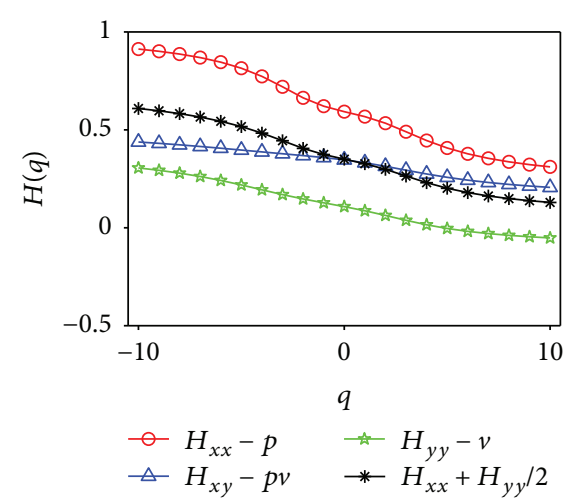

(h)

Figure 6: The generalized Hurst exponent values of $H_{x x}, H_{y y}, H_{x y}$, and the value $\left(H_{x x}+H_{y y}\right) / 2$ for different $q$ values.

exponent $H_{x y}$ has similar properties and interpretation as the univariate Hurst exponent. Figure 6 shows the relationship between the generalized Hurst exponents $H_{x x}, H_{y y}$, and $H_{x y}$. In our findings, for the Bitcoin market, the crosscorrelation exponent is less than the average generalized Hurst exponent for $q>0$. This result is consistent with the conclusions of the agricultural future market [59] and the gold market [10].

If $H$ is a constant, the time series is monofractal; otherwise, it is multifractal. As we can see in Figure 6, the cross- correlation of return-volume has been declining, indicating that all the eight exchange rates have multifractal features. In particular, the Hurst exponent $H_{x x}(q)$ is greater than 0.5 , $H_{x y}(q)$ and $H_{y y}(q)$ for $q<0$, which means that the price behavior of small fluctuations is more persistent than the volume and cross-correlation behavior. In contrast, the antipersistence of the volume is stronger for $q>0$. Because the cross-correlation Hurst exponent $H_{x y}(2)<0.5$, we can see that there is an antipersistent cross-correlated behavior of return-volume in the Bitcoin market. 


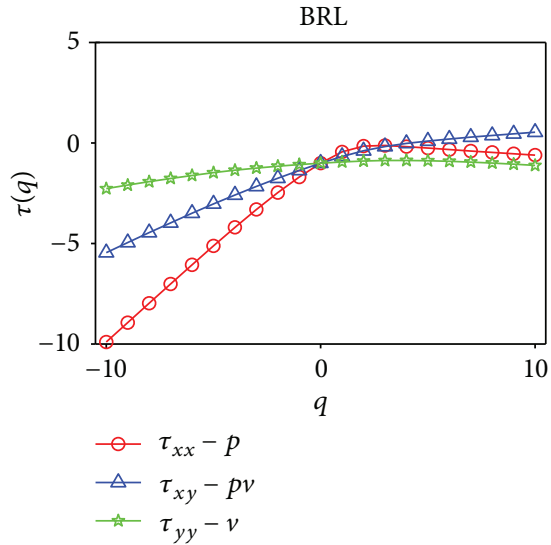

(a)

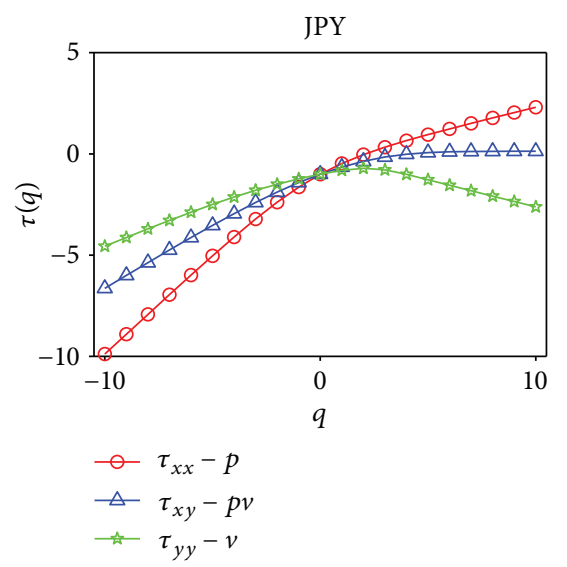

(d)

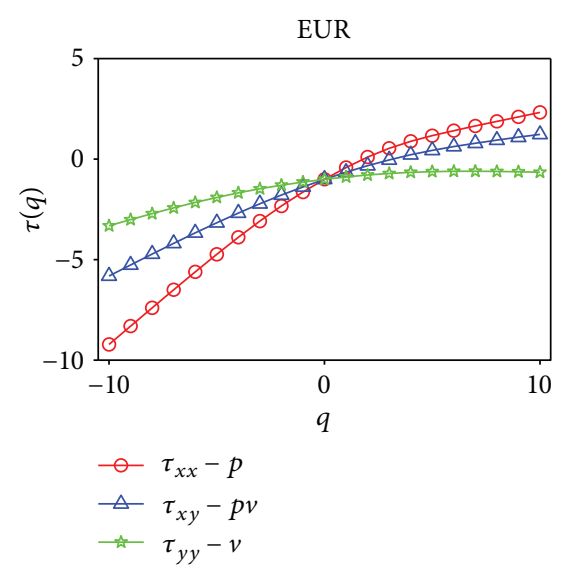

(b)

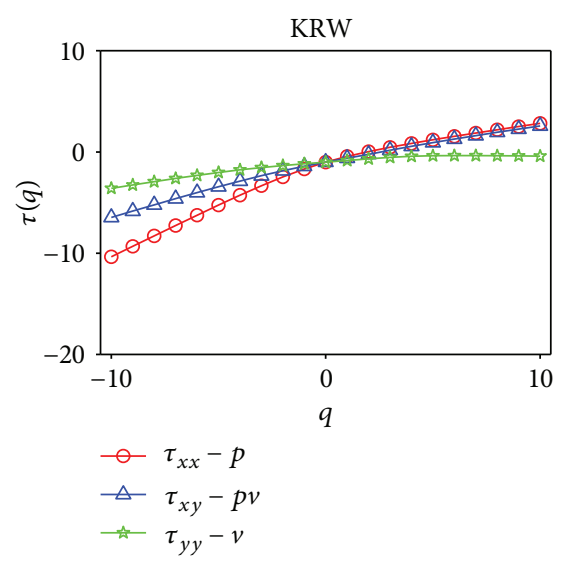

(e)

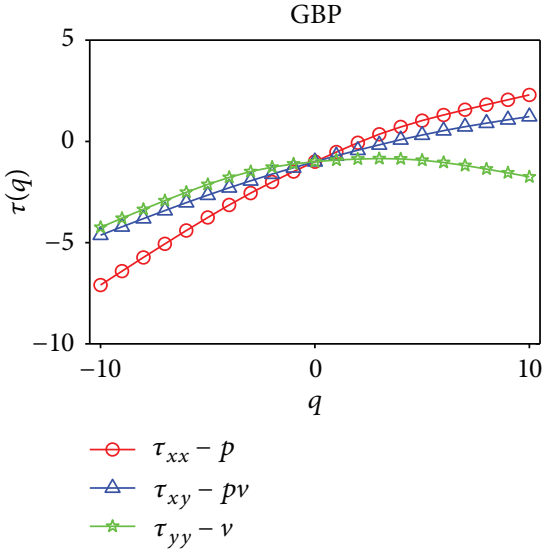

(c)

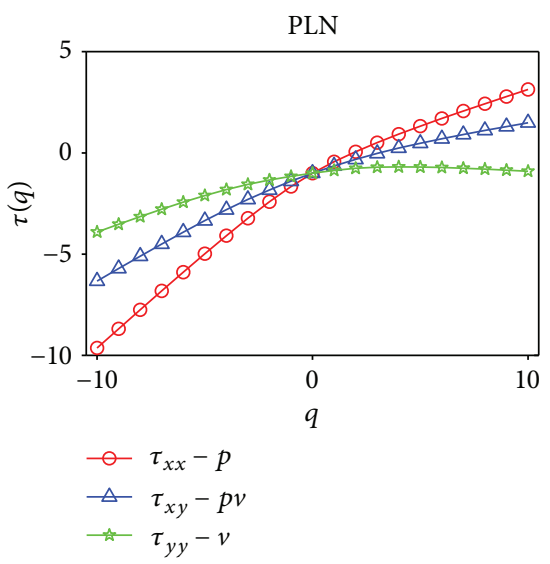

(f)

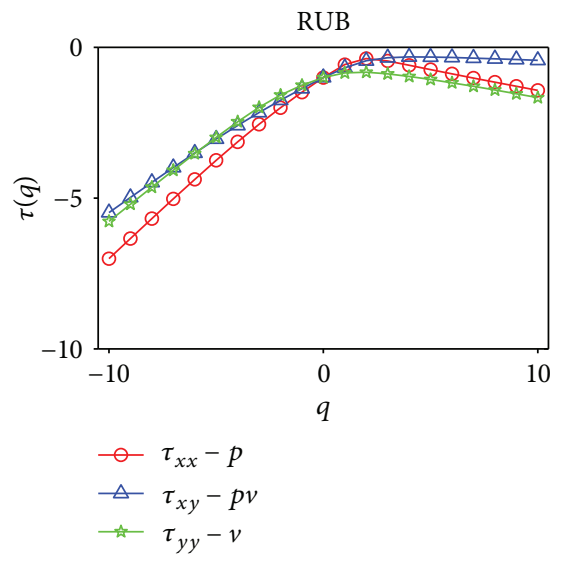

(g)

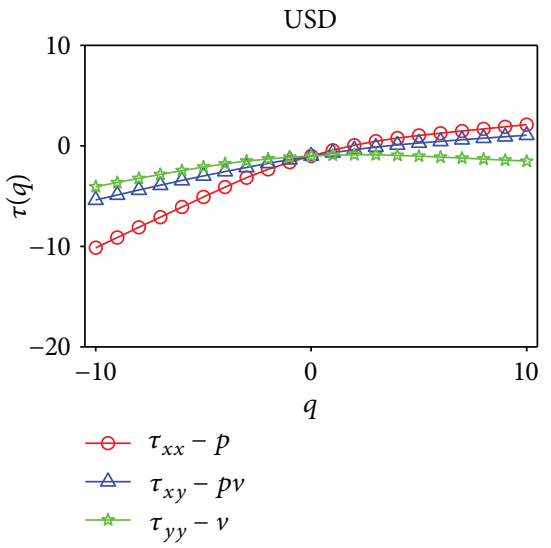

(h)

Figure 7: The mass exponent values of $\tau(q)$ for different $q$ values.

According to (7), we calculate the Renyi exponent $\tau_{x y}(q)$ that characterizes the multifractality. The legends $\tau_{x x}-p, \tau_{y y}-p$, and $\tau_{x y}-p v$ in Figure 7 denote the Renyi exponent of price, volume, and bivariate. According to Figure $7, \tau_{x y}(q)$ is the nonlinear curves of the eight exchange rates dependent on $q$.

Then, we employ (8) and (9) to calculate the multifractal spectrum of the eight exchange rates. The $\Delta \alpha$ in (10) means the degree of multifractality. The larger $\Delta \alpha$ implies stronger multifractality and lower $\Delta \alpha$ indicates weaker multifractal behavior. If $\Delta \alpha$ is close to zero, it is monofractal. According to Figure 8 , the multifractal spectra of the eight exchange rates are not a point; there exist the multifractal characteristics of return-volume. The width of the multifractal spectrum of BRL and RUB is obviously different, and the price spectrum width is larger than the sum of the volume spectrum width and price-volume spectrum width. This may be related to the Russian ban on Bitcoin. As early as January 2014, 


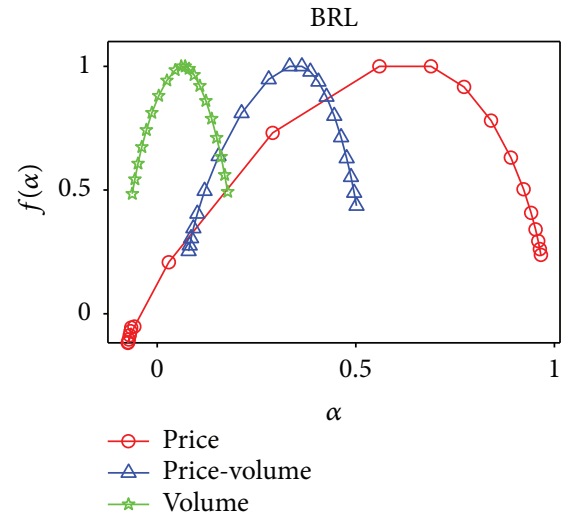

(a)

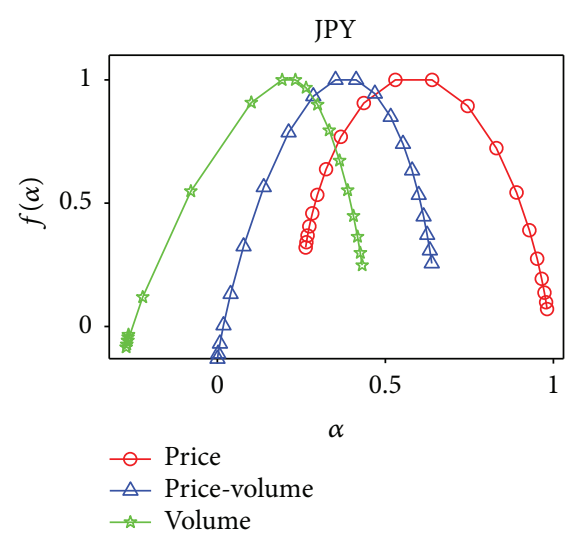

(d)

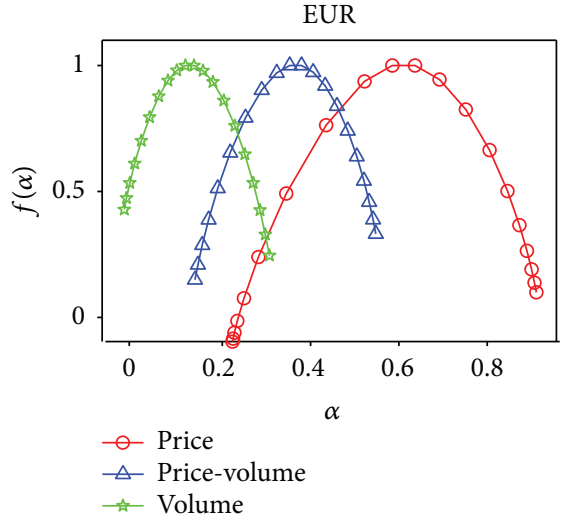

(b)

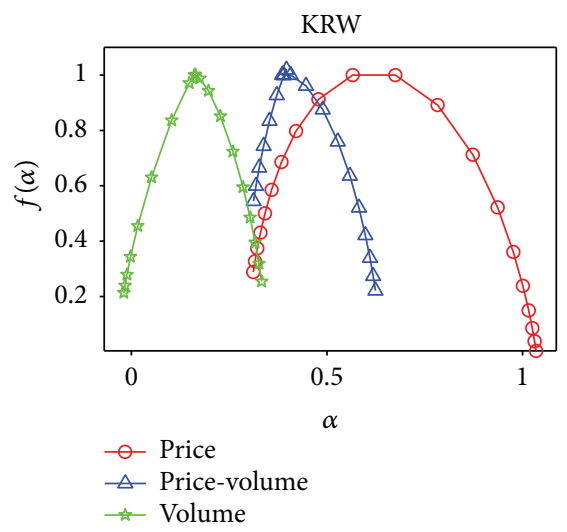

(e)

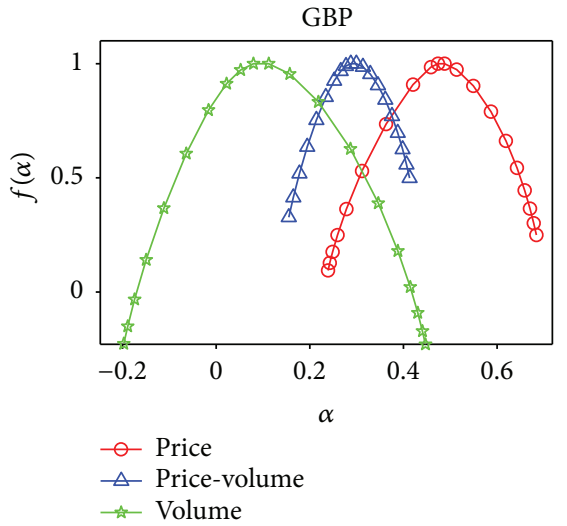

(c)

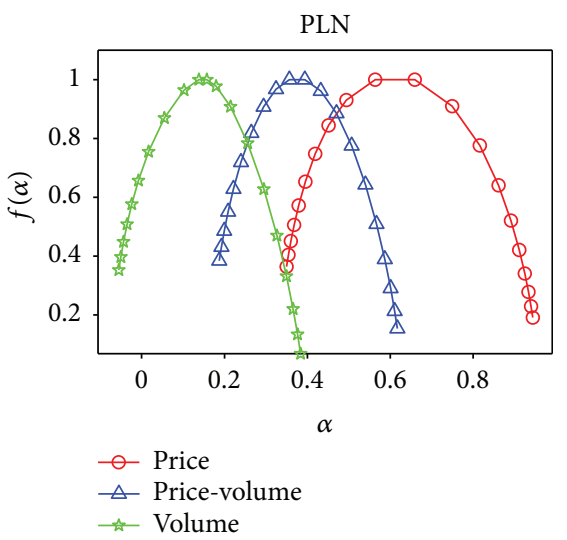

(f)

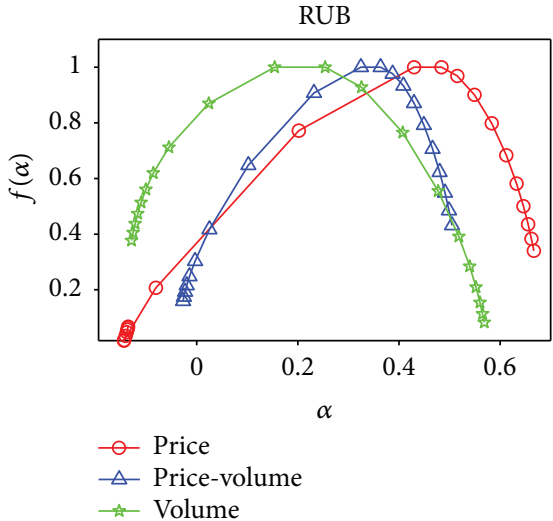

(g)

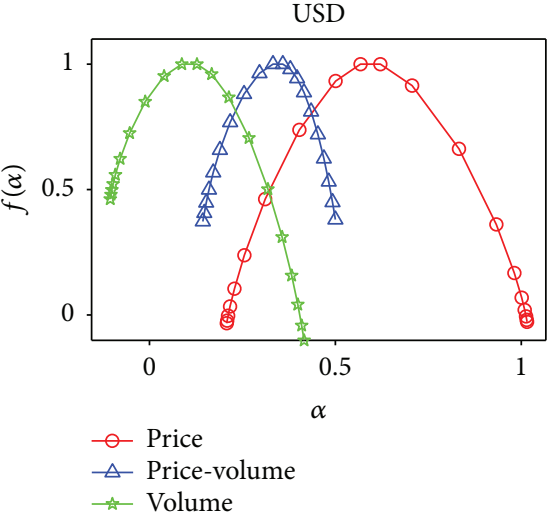

(h)

FIGURE 8: The multifractal spectrum $f(\alpha)$ as a function of $\alpha$.

Russian officials issued a statement that it was illegal to issue agency currency in Russia. In the ensuing period, various stakeholders have been wrestling for many times. The policy on the issuance and circulation of cryptocurrencies has also changed several times ("A Concise History of the Bitcoin Ban in Russia"; please refer to: http://www.coinfox.info/ news/reviews/5982-a-concise-history-of-the-bitcoin-ban-inrussia). In the early 2018, Russia finalized the federal law on cryptocurrency regulation (http://Bitcion.com/ reported this news: https://news.bitcoin.com/russia-finalizes-federal-lawcryptocurrency-regulation).
4.3. Long-Term and Short-Term Analysis. We define "crossover" $S^{*}$ as a turning point when the linear tendency of the curve changes fundamentally. Short-term market behavior is very vulnerable to external market factors, while longterm behavior is mainly determined by the internal factors of assets. With time going by, the short-term impact will gradually decay; the long-term market supply and demand mechanisms will play a role. When $s<S^{*}$, the scale exponent means short-term-related behavior. And when $s>S^{*}$, the scale exponent reflects long-term-related behavior. According to Figure 4, we find that the "crossover" of the top eight 


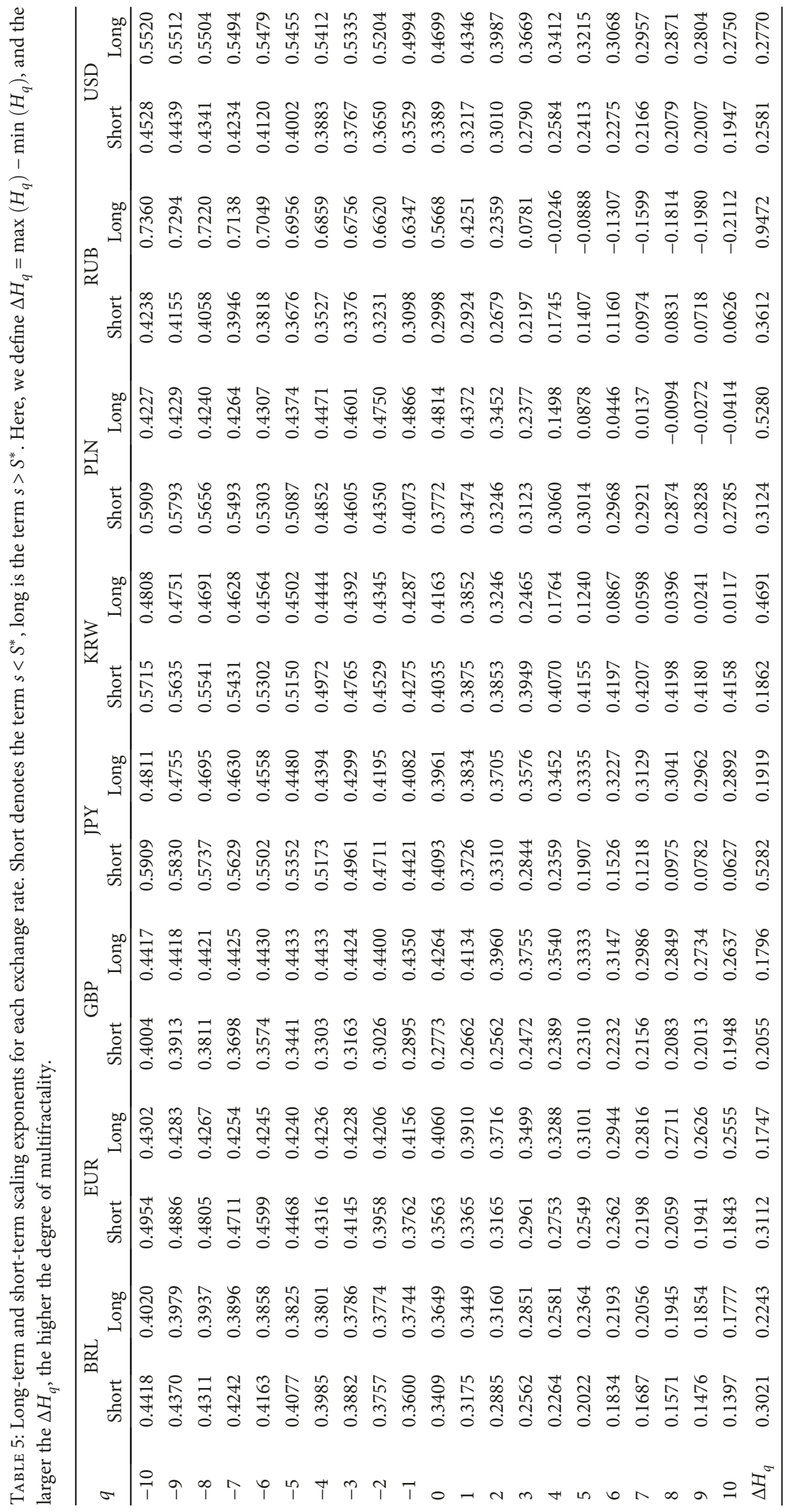




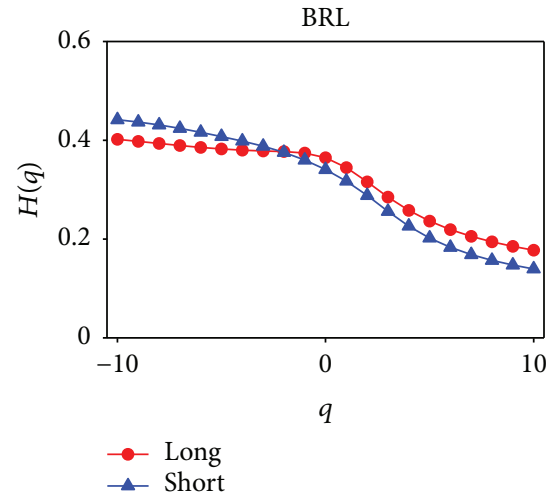

(a)

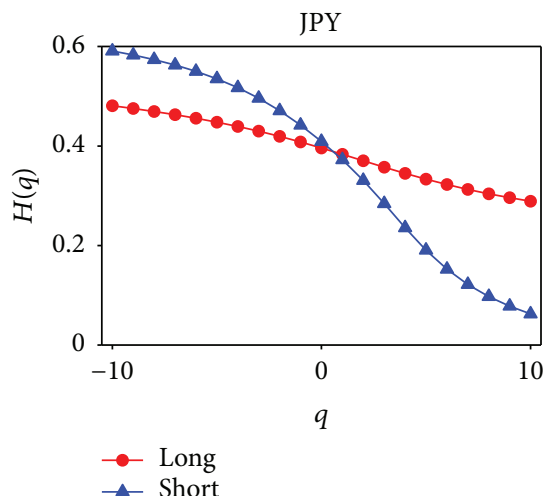

(d)

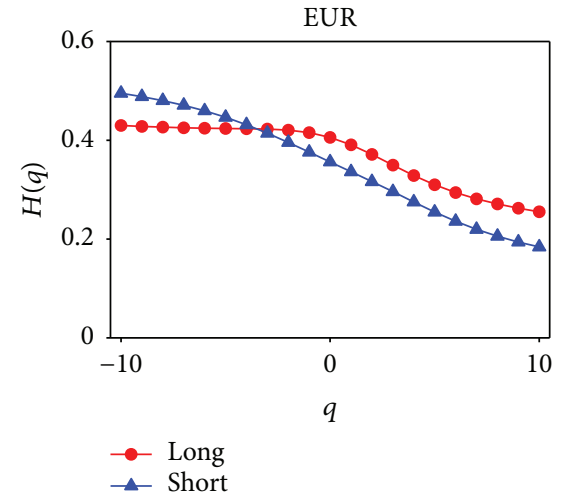

(b)

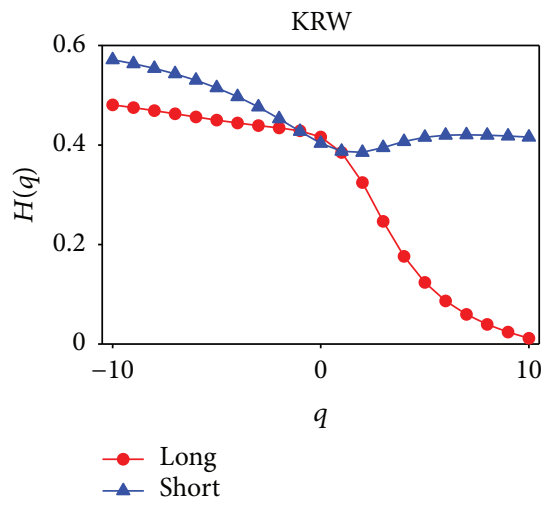

(e)

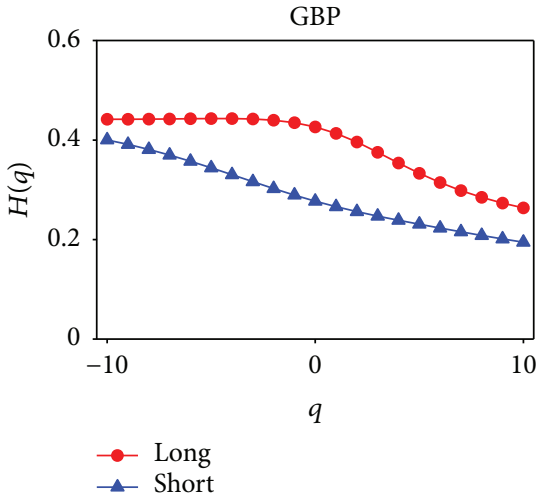

(c)

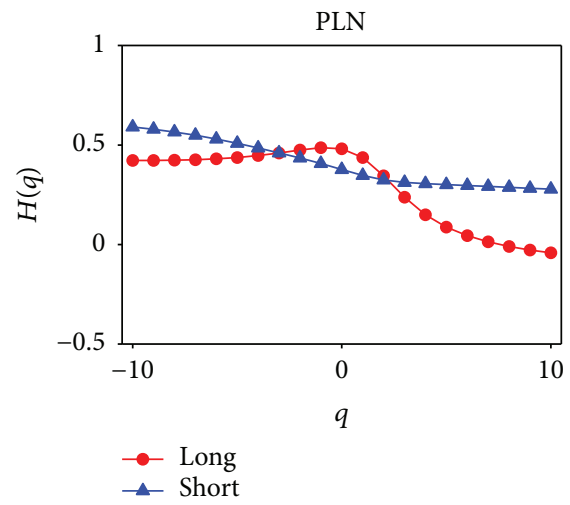

(f)

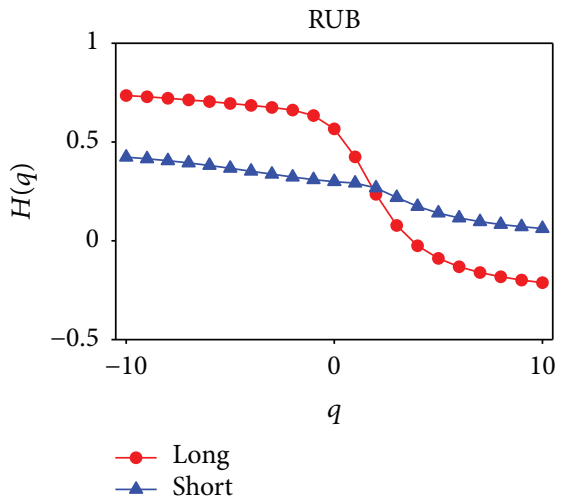

(g)

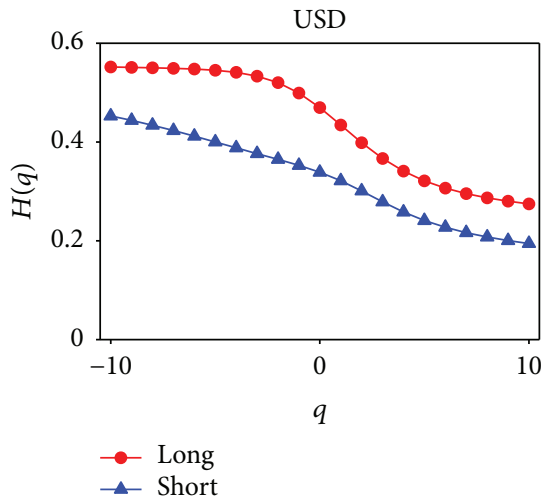

(h)

FIgURE 9: The long-term and short-term generalized Hurst exponent values $H_{x y}$.

exchange rates (BRL, EUR, GBP, JPY, KRW, PLN, RUB, and USD) is located at approximately $\log \left(S^{*}=2.1761\right)$ (150 days, about 5 months), $\log \left(S^{*}=2.2788\right)$ (190 days, about 6.3333 months), $\log \left(S^{*}=2.3222\right)$ (210 days, about 7 months), $\log \left(S^{*}=2.1461\right)$ (140 days, about 4.6667 months), $\log \left(S^{*}=2.0792\right) \quad(120$ days, about 4 months $), \log \left(S^{*}=\right.$ 2.301) (200 days, about 6.6667 months), $\log \left(S^{*}=2.415\right)$ (260 days, about 8.6667 months), and $\log \left(S^{*}=2.4472\right)$ (280 days, about 9.3333 months), respectively.

To study the different long-term and short-term changes in the cross-correlation, we calculate the cross-correlation scaling exponents for $q$ from -10 to 10 . Table 5 reports the long-term and short-term scaling exponents. $\Delta H_{q}$ denotes the degree of multifractality. KRW, PLN, RUB, and USD are strongly multifractal in the long term than the short term, while the rest is the opposite. From Figure 9, for the highest degree of fractal exchange rate, RUB, long-term scaling exponent is greater than 0.5 when $q<0$, indicating that the cross-correlation of small fluctuations in the long-term persists (positive), while almost all the exponents of the other exchange rates are less than 0.5 in the long term. Long-term and short-term exponents of BRL, EUR, and GBP are less than 0.5 with $q$ varying from -10 to 10 . For EUR and GBP, the long-term value of $H_{x y}(q)$ is weakly dependent on $q$, indicating that longterm cross-correlation is weakly multifractal. Long-term 


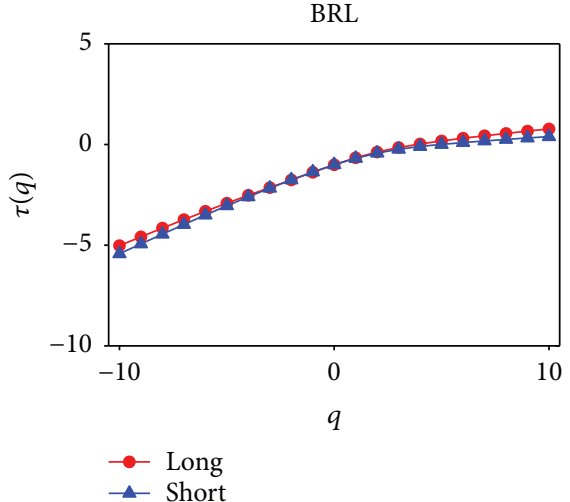

(a)

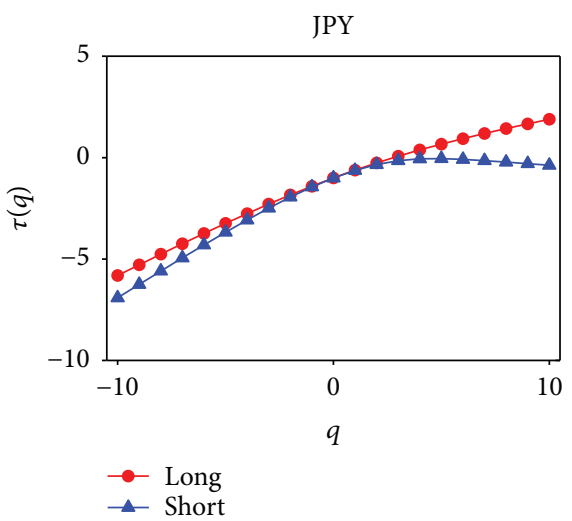

(d)

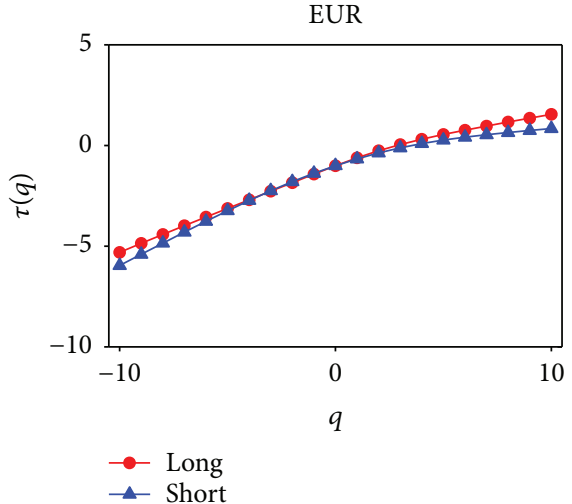

(b)

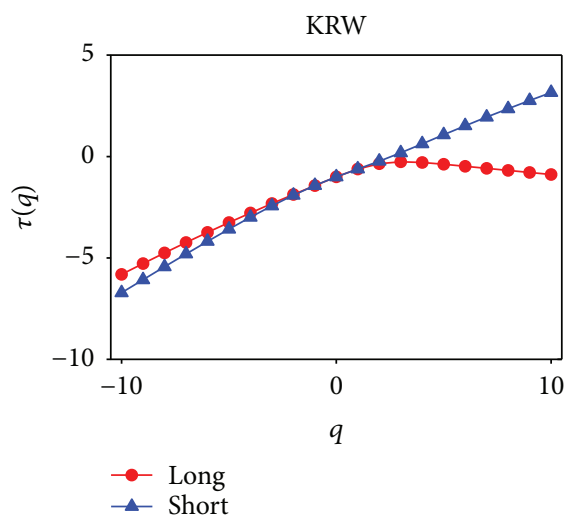

(e)

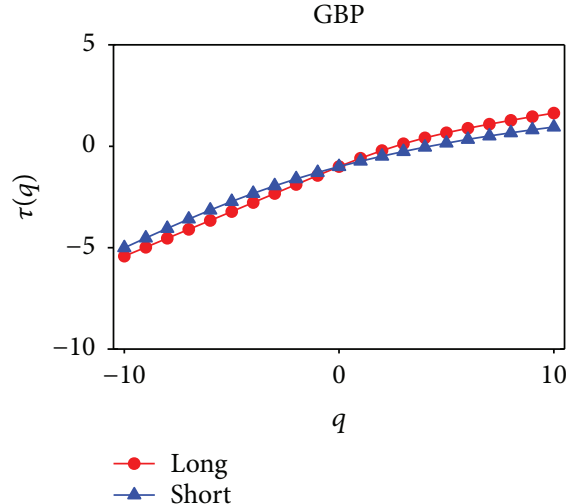

(c)

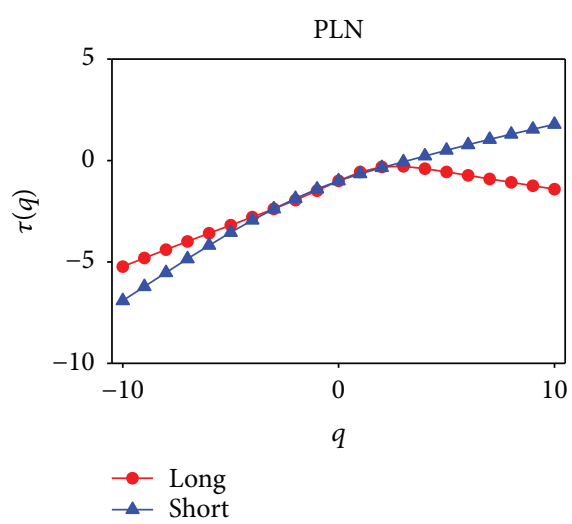

(f)

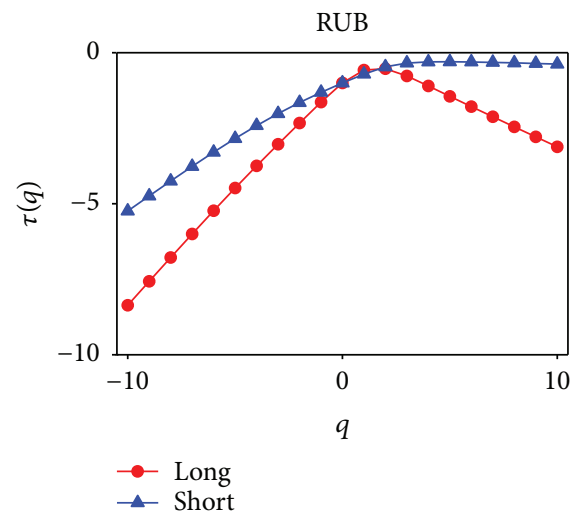

(g)

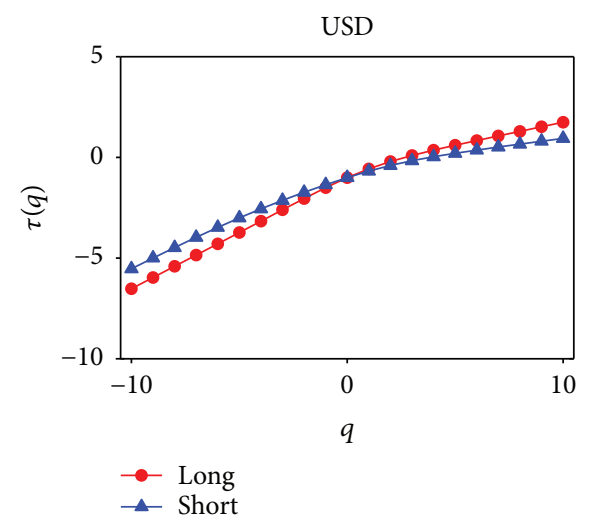

(h)

FIGURE 10: The long-term and short-term mass exponent values of $\tau_{x y}(q)$.

and short-term scaling exponents $H_{x y}(2)$ of all exchange rates are all less than 0.5 , indicating antipersistent crosscorrelations. This conclusion is consistent with the findings in Section 4.2. Besides, the particularity of RUB may require further analysis.

From Figure 10, we find the $\tau_{x y}(q)$ of KRW, PLN, and RUB are more curved in the long term, which indicates that the three exchange rates are more multifractal in the long term. The rest exchange rates are the opposite. This evidence supports the findings of Table 5.

In Figure 11, although some points are clustered together, the $\Delta \alpha$ is not zero. As can be seen from Figure 11, the multifractal strength of the spectrum of RUB in the long term is the largest, which means the multifractal degree of RUB is stronger than others. The multifractalities of KRW, PLN, RUB, and USD are stronger in the long term, while the spectra of the rest are just the opposite.

4.4. Rolling Window Analysis. The method of rolling windows is very popular in the financial field due to its ability to analyze the dynamics of time series. The result of the rolling method depends on the window length. In particular, if the length is set too short, short-term fluctuations may be very dramatic; we may not be able to accurately determine 


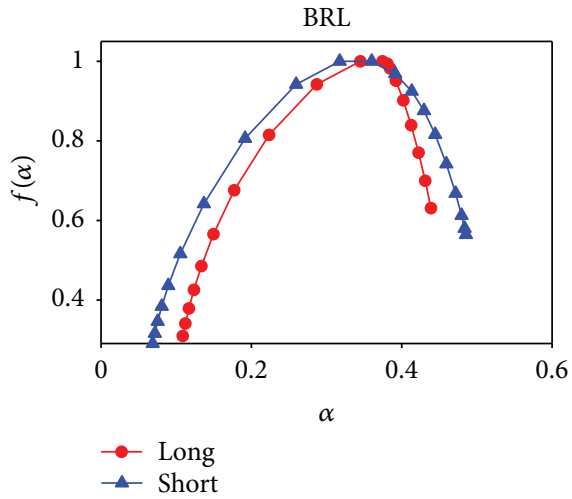

(a)

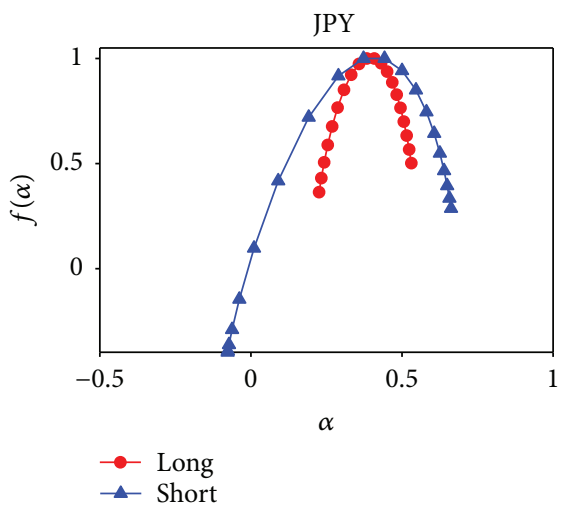

(d)

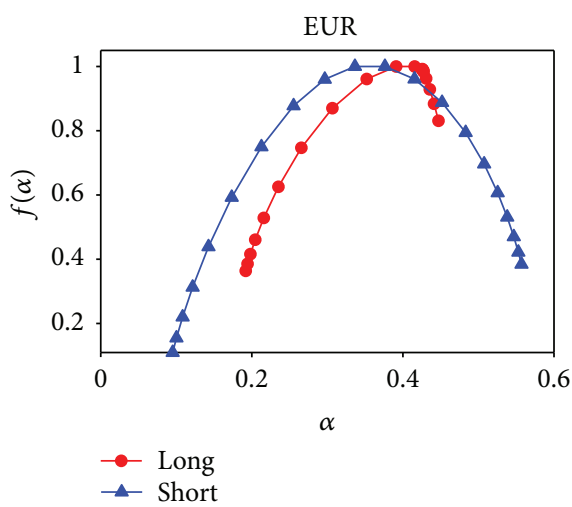

(b)

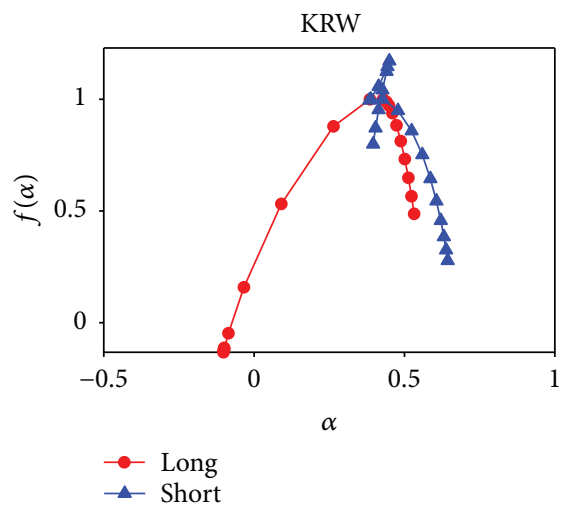

(e)

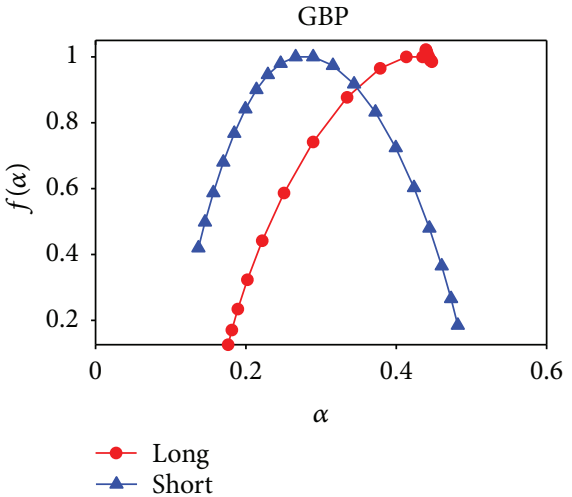

(c)

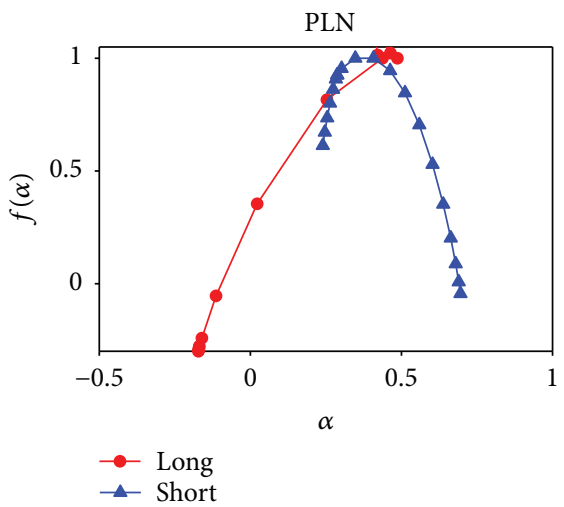

(f)

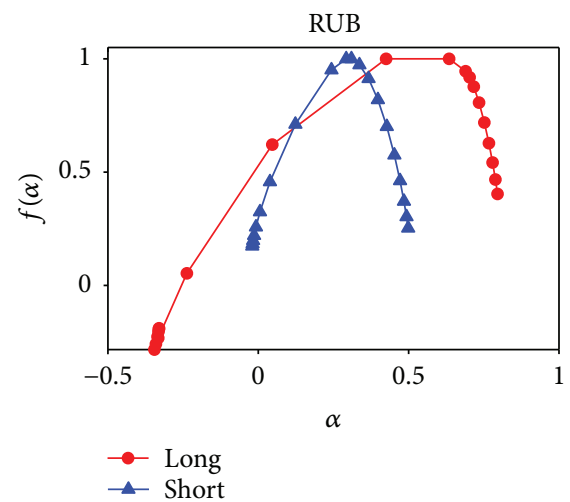

(g)

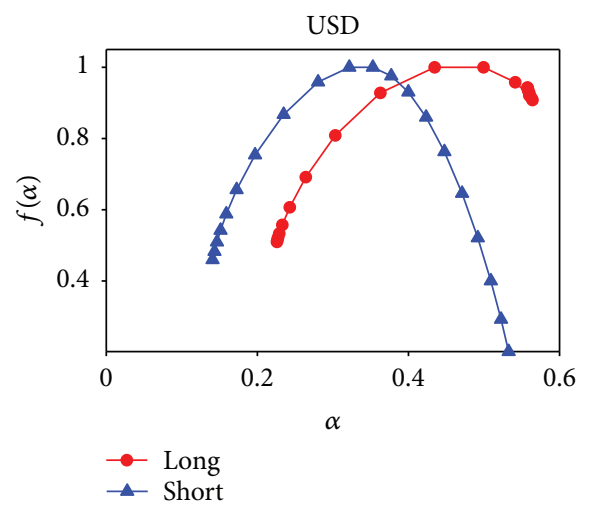

(h)

FIGURE 11: The long-term and short-term multifractal spectrum $f_{x y}(\alpha)$.

the long-term trend. If the length is set too long, we cannot observe the local detail changes.

According to the previous study of Bitcoin using the rolling window approach $[15,16]$, in this paper, we use a 500-day sliding window to estimate the scaling exponents. Specifically, we use the overlay window to move forward the one-day data point.

The legends $\mathrm{H}_{x x}-p, \mathrm{H}_{y y}-v$, and $\mathrm{H}_{x y}-p v$ in Figure 12 denote price, volume, and bivariate. The blue line and green line are the Hurst exponents of price, respectively, by employing DFA. And the red line is the exponent for the cross-correlation for return-volume. The green lines in the eight charts of Figure 12 are less than 0.5 over the entire sample period, which means the volume change is antipersistent. The blue lines of BRL, EUR, JPY, KRW, and PLN are greater than 0.5, which means Bitcoin is not efficient in those markets. The GBP price exponent trend is first to decline and then rise. In the chart of USD, the Hurst exponent of price is greater than 0.5 before 2014 and wanders around 0.5 after 2014, which means USD-denominated Bitcoin is in the process of moving efficiently. This evidence supports the conclusion of Urquhart [14] and Bariviera [15]. The price Hurst exponent of RUB is less than 0.5. And this is another proof of the special nature of the RUB. All the scaling 
BRL

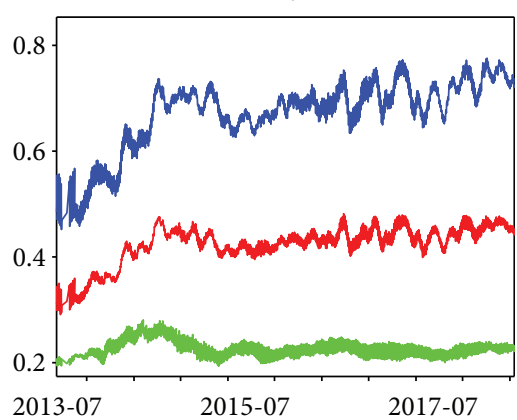

$\begin{array}{ll}- & H_{x x}-p \\ - & H_{x v}-p v \\ - & H_{y y}-v\end{array}$

(a)

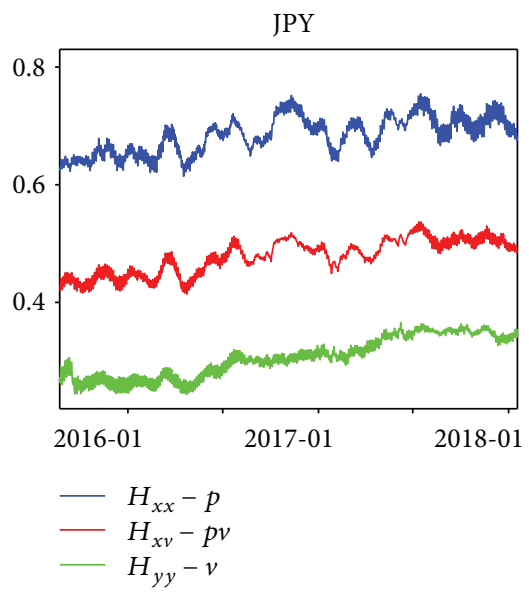

(d)

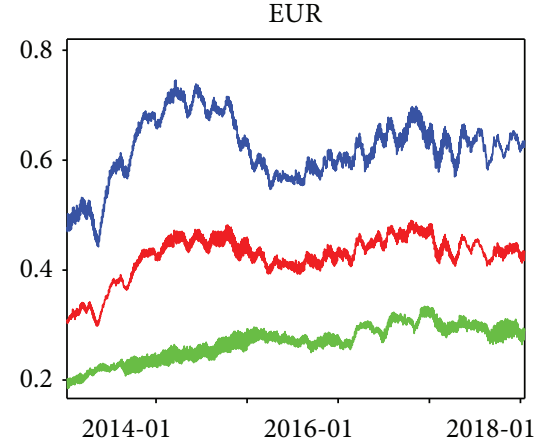

$\begin{array}{ll}- & H_{x x}-p \\ - & H_{x v}-p v \\ - & H_{y y}-v\end{array}$

(b)

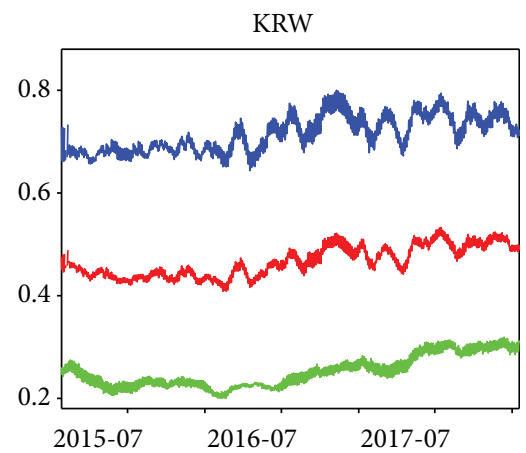

$-H_{x x}-p$

$-H_{x v}-p v$

$-H_{y y}-v$

(e)

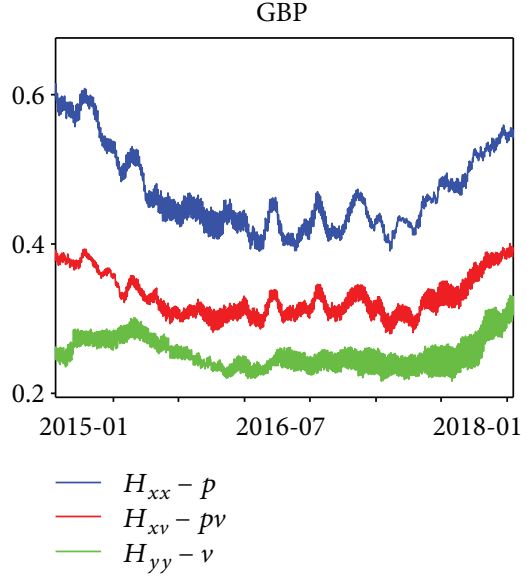

(c)

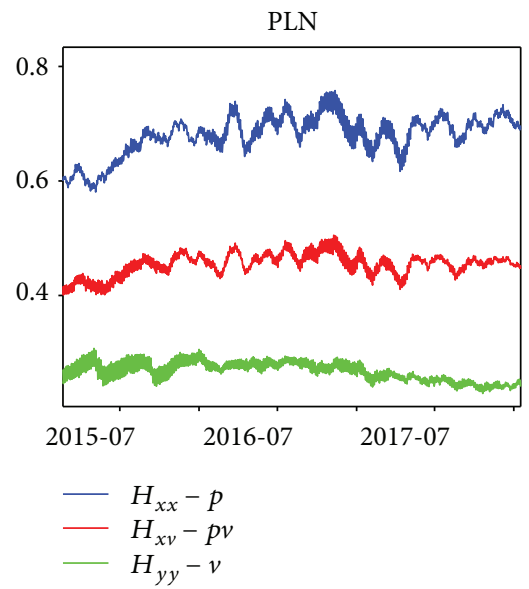

(f)

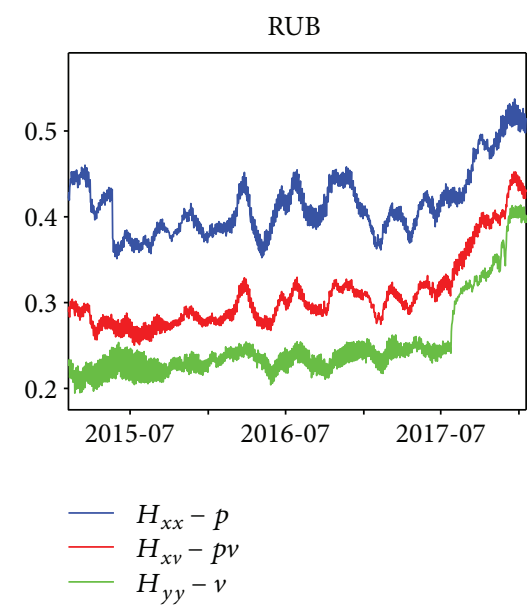

(g)

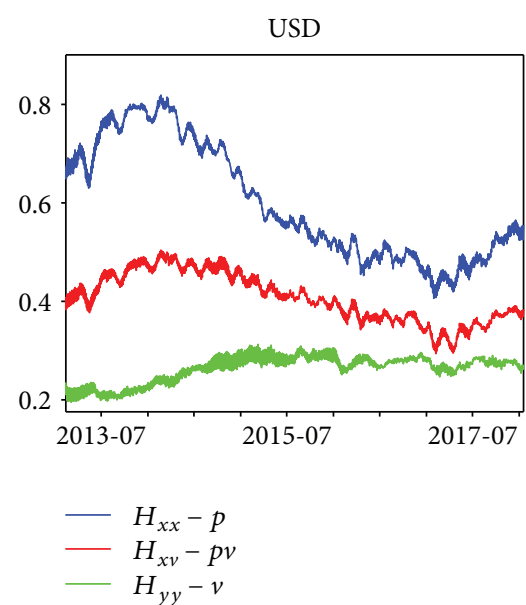

(h)

FIGURE 12: Time varying scaling exponents when $q=2$.

exponents of the cross-correlation are less than 0.5 , indicating that returns and price are not persistently crosscorrelated. In particular, the exponent of the RUB is lower and wanders around 0.3 , which indicates the crosscorrelation of RUB is more antipersistently cross-correlated (under the circumstance that $H_{x y}$ is less than 0.5 which means antipersistenly cross-correlated, if $H_{x y}$ of RUB is smaller than that of other currencies when they are both less than 0.5 , we say RUB is more antipersistently cross-correlated). The RUB rise of the scaling exponents of the crosscorrelation after July 2017 may be related to the madness of the global Bitcoin market. 


\section{Concluding Remarks}

We selected the most actively traded markets in the world and synthesize the composite index of the top eight exchange rates with the highest volume on the basis of the volumeweighted composite index. In particular, we conduct the cross-correlation test with multifractal detrended crosscorrelation analysis (MF-DCCA), and the empirical results show that first, the global Bitcoin markets are not fully synchronized. The statistics and multifractal features of Bitcoin denominated in different exchange rates are very different. Among them, the RUB is most evident. Second, we use the cross-correlation test statistic $Q_{c c}$ to find the nonlinear dependencies and power-law cross-correlations in returnvolume relationship in all of the Bitcoin markets. Third, all cross-correlations of the eight exchange rates are multifractal. The cross-correlation Hurst exponent $H_{x y}(2)<0.5$, which means antipersistent behavior for the return-volume in the Bitcoin markets. The cross-correlation exponent $H_{x y}$ is less than the average generalized Hurst exponent for $q>0$. And the price behavior of small fluctuations is more persistent than the volume and cross-correlation behavior, while the volume of larger fluctuations is more antipersistent. Fourth, we find that the bivariate cross-correlation exponent is less than 0.5 by employing a rolling window method. This indicates that the cross-correlation of return-volume is antipersistent with time going by. It would be interesting to investigate the impacts of the policy changes on the returnvolume relationship of the Bitcoin market. We leave this for future research.

\section{Data Availability}

The data used to support the findings of this study are available from the corresponding author upon request.

\section{Conflicts of Interest}

The authors declare that there are no conflicts of interest regarding the publication of this article.

\section{Acknowledgments}

The authors thank one anonymous referee for the useful suggestions that helped improve the paper substantially. This work is supported by the National Natural Science Foundation of China (71701150, 71790594, and 71532009), Young Elite Scientists Sponsorship Program by Tianjin (TJSQNTJ2017-09), and Fundamental Research Funds for the Central Universities (63182064).

\section{References}

[1] D. G. Baur, K. Hong, and A. D. Lee, "Bitcoin: medium of exchange or speculative assets?," Journal of International Financial Markets, Institutions and Money, vol. 54, pp. 177189, 2018.

[2] B. M. Blau, "Price dynamics and speculative trading in Bitcoin," Research in International Business and Finance, vol. 43, pp. 15-21, 2018.
[3] S. Corbet, B. Lucey, and L. Yarovya, "Datestamping the Bitcoin and Ethereum bubbles," Finance Research Letters, 2017.

[4] A. H. Dyhrberg, "Hedging capabilities of bitcoin. Is it the virtual gold?," Finance Research Letters, vol. 16, pp. 139144, 2016.

[5] D. G. Baur, T. Dimpfl, and K. Kuck, "Bitcoin, gold and the US dollar - a replication and extension," Finance Research Letters, vol. 25, pp. 103-110, 2018.

[6] M. El Alaoui, "Price-volume multifractal analysis of the Moroccan stock market," Physica A: Statistical Mechanics and its Applications, vol. 486, pp. 473-485, 2017.

[7] D. Stošić, D. Stošić, T. Stošić, and H. Eugene Stanley, "Multifractal properties of price change and volume change of stock market indices," Physica A: Statistical Mechanics and its Applications, vol. 428, pp. 46-51, 2015.

[8] D.-H. Wang, Y.-Y. Suo, X.-W. Yu, and M. Lei, "Price-volume cross-correlation analysis of CSI300 index futures," Physica A: Statistical Mechanics and its Applications, vol. 392, no. 5, pp. 1172-1179, 2013.

[9] Y. Yuan, X.-T. Zhuang, and Z.-Y. Liu, "Price-volume multifractal analysis and its application in Chinese stock markets," Physica A: Statistical Mechanics and its Applications, vol. 391, no. 12, pp. 3484-3495, 2012.

[10] Q. Ruan, W. Jiang, and G. Ma, "Cross-correlations between price and volume in Chinese gold markets," Physica A: Statistical Mechanics and its Applications, vol. 451, pp. 10-22, 2016.

[11] L.-Y. He and S.-P. Chen, "Nonlinear bivariate dependency of price-volume relationships in agricultural commodity futures markets: a perspective from multifractal detrended crosscorrelation analysis," Physica A: Statistical Mechanics and its Applications, vol. 390, no. 2, pp. 297-308, 2011.

[12] S. Nadarajah and J. Chu, "On the inefficiency of Bitcoin," Economics Letters, vol. 150, pp. 6-9, 2017.

[13] W. Zhang, P. Wang, X. Li, and D. Shen, The Inefficiency of Cryptocurrency and Its Cross-Correlation with Dow Jones Industrial Average, Working paper, 2018.

[14] A. Urquhart, "The inefficiency of Bitcoin," Economics Letters, vol. 148, pp. 80-82, 2016.

[15] A. F. Bariviera, "The inefficiency of Bitcoin revisited: a dynamic approach," Economics Letters, vol. 161, pp. 1-4, 2017.

[16] A. F. Bariviera, M. J. Basgall, W. Hasperué, and M. Naiouf, "Some stylized facts of the Bitcoin market," Physica A: Statistical Mechanics and its Applications, vol. 484, pp. 82-90, 2017.

[17] Y. Jiang, H. Nie, and W. Ruan, "Time-varying long-term memory in Bitcoin market," Finance Research Letters, vol. 25, pp. $280-284,2018$.

[18] J. Alvarez-Ramirez, E. Rodriguez, and C. Ibarra-Valdez, "Long-range correlations and asymmetry in the Bitcoin market," Physica A: Statistical Mechanics and its Applications, vol. 492, pp. 948-955, 2018.

[19] W. Zhang, P. Wang, X. Li, and D. Shen, "Some stylized facts of the cryptocurrency market," Applied Economics, pp. 1-16, 2018.

[20] E. Bouri, P. Molnár, G. Azzi, D. Roubaud, and L. I. Hagfors, "On the hedge and safe haven properties of Bitcoin: is it really more than a diversifier?," Finance Research Letters, vol. 20, pp. 192-198, 2017.

[21] S. Corbet, A. Meegan, C. Larkin, B. Lucey, and L. Yarovaya, "Exploring the dynamic relationships between cryptocurrencies and other financial assets," Economics Letters, vol. 165, pp. 28-34, 2018. 
[22] D. Shen, X. Li, and W. Zhang, "Baidu news information flow and return volatility: evidence for the sequential information arrival hypothesis," Economic Modelling, vol. 69, pp. 127133, 2018.

[23] X. Li, D. Shen, and W. Zhang, "Do Chinese internet stock message boards convey firm-specific information?," PacificBasin Finance Journal, vol. 49, pp. 1-14, 2018.

[24] W. Zhang, D. Shen, Y. Zhang, and X. Xiong, "Open source information, investor attention, and asset pricing," Economic Modelling, vol. 33, pp. 613-619, 2013.

[25] A. Urquhart, "What causes the attention of Bitcoin?," Economics Letters, vol. 166, pp. 40-44, 2018.

[26] W. Zhang, P. Wang, X. Li, and D. Shen, "Quantifying the cross-correlations between online searches and Bitcoin market," Physica A: Statistical Mechanics and its Applications, vol. 509, pp. 657-672, 2018.

[27] B. B. Mandelbrot, The Fractal Geometry of Nature, Freeman, New York, NY, USA, 1983.

[28] H. E. Hurst, "Long term storage capacity of reservoirs," ASCE Transactions, vol. 116, no. 776, pp. 770-808, 1951.

[29] H. E. Hurst, "A suggested statistical model of some time series which occur in nature," Nature, vol. 180, no. 4584, p. 494, 1957.

[30] A. W. Lo, Long-Term Memory in Stock Market Prices, National Bureau of Economic Research, 1989.

[31] C.-K. Peng, S. V. Buldyrev, S. Havlin, M. Simons, H. E. Stanley, and A. L. Goldberger, "Mosaic organization of DNA nucleotides," Physical Review E, vol. 49, no. 2, pp. 1685-1689, 1994.

[32] Z.-Q. Jiang, W.-J. Xie, and W.-X. Zhou, "Testing the weakform efficiency of the WTI crude oil futures market," Physica A: Statistical Mechanics and its Applications, vol. 405, pp. 235-244, 2014.

[33] J. W. Kantelhardt, S. A. Zschiegner, E. Koscielny-Bunde, S. Havlin, A. Bunde, and H. E. Stanley, "Multifractal detrended fluctuation analysis of nonstationary time series," Physica A: Statistical Mechanics and its Applications, vol. 316, no. 1-4, pp. 87-114, 2002.

[34] B. Podobnik and H. E. Stanley, "Detrended cross-correlation analysis: a new method for analyzing two nonstationary time series," Physical Review Letters, vol. 100, no. 8, article 084102, 2008.

[35] W.-X. Zhou, "Multifractal detrended cross-correlation analysis for two nonstationary signals," Physical Review E, vol. 77, no. 6, article 066211, 2008.

[36] X.-Y. Qian, Y.-M. Liu, Z.-Q. Jiang, B. Podobnik, W.-X. Zhou, and H. E. Stanley, "Detrended partial cross-correlation analysis of two nonstationary time series influenced by common external forces," Physical Review E, vol. 91, no. 6, article 062816, 2015.

[37] Z.-Q. Jiang and W.-X. Zhou, "Multifractal detrending movingaverage cross-correlation analysis," Physical Review E, vol. 84, no. 1, article 016106, 2011.

[38] L. Kristoufek, "Multifractal height cross-correlation analysis: a new method for analyzing long-range cross-correlations," $E P L$ (Europhysics Letters), vol. 95, no. 6, article 68001, 2011.

[39] J. Wang, P. Shang, and W. Ge, "Multifractal cross-correlation analysis based on statistical moments," Fractals, vol. 20, no. 03n04, pp. 271-279, 2012.

[40] C. Xie, Y. Zhou, G. Wang, and X. Yan, "Analyzing the crosscorrelation between onshore and offshore RMB exchange rates based on multifractal Detrended cross-correlation analysis (MF-DCCA)," Fluctuation and Noise Letters, vol. 16, no. 1, article 1750004, 2017.

[41] J. Li, X. Lu, and Y. Zhou, "Cross-correlations between crude oil and exchange markets for selected oil rich economies," Physica A: Statistical Mechanics and its Applications, vol. 453, pp. 131143, 2016.

[42] F. Ma, Y. Wei, and D. Huang, "Multifractal detrended cross-correlation analysis between the Chinese stock market and surrounding stock markets," Physica A: Statistical Mechanics and its Applications, vol. 392, no. 7, pp. 16591670, 2013.

[43] Y. Wang, Y. Wei, and C. Wu, "Cross-correlations between Chinese A-share and B-share markets," Physica A: Statistical Mechanics and its Applications, vol. 389, no. 23, pp. 5468$5478,2010$.

[44] P. Yue, H.-C. Xu, W. Chen, X. Xiong, and W.-X. Zhou, "Linear and nonlinear correlations in the order aggressiveness of Chinese stocks," Fractals, vol. 25, no. 5, 2017.

[45] F. Ma, Y. Wei, D. Huang, and L. Zhao, "Cross-correlations between West Texas Intermediate crude oil and the stock markets of the BRIC," Physica A: Statistical Mechanics and its Applications, vol. 392, no. 21, pp. 5356-5368, 2013.

[46] F. Ma, Q. Zhang, C. Peng, and Y. Wei, "Multifractal detrended cross-correlation analysis of the oil-dependent economies: evidence from the West Texas Intermediate crude oil and the GCC stock markets," Physica A: Statistical Mechanics and its Applications, vol. 410, pp. 154-166, 2014.

[47] Y. Wang, Y. Wei, and C. Wu, "Detrended fluctuation analysis on spot and futures markets of West Texas Intermediate crude oil," Physica A: Statistical Mechanics and its Applications, vol. 390, no. 5, pp. 864-875, 2011.

[48] X. Zhuang, Y. Wei, and F. Ma, "Multifractality, efficiency analysis of Chinese stock market and its cross-correlation with WTI crude oil price," Physica A: Statistical Mechanics and its Applications, vol. 430, pp. 101-113, 2015.

[49] X. Zhuang, Y. Wei, and B. Zhang, "Multifractal detrended cross-correlation analysis of carbon and crude oil markets," Physica A: Statistical Mechanics and its Applications, vol. 399, pp. 113-125, 2014.

[50] Y. Wang, Y. Wei, and C. Wu, "Analysis of the efficiency and multifractality of gold markets based on multifractal detrended fluctuation analysis," Physica A: Statistical Mechanics and its Applications, vol. 390, no. 5, pp. 817-827, 2011.

[51] X. Lu, J. Li, Y. Zhou, and Y. Qian, "Cross-correlations between RMB exchange rate and international commodity markets," Physica A: Statistical Mechanics and its Applications, vol. 486, pp. 168-182, 2017.

[52] Z. Zhang, Y. Zhang, D. Shen, and W. Zhang, "The dynamic cross-correlations between mass media news, new media news, and stock returns," Complexity, vol. 2018, Article ID 7619494, 11 pages, 2018.

[53] Z. Zhang, Y. Zhang, D. Shen, and W. Zhang, "The crosscorrelations between online sentiment proxies: evidence from Google Trends and Twitter," Physica A: Statistical Mechanics and its Applications, vol. 508, pp. 67-75, 2018.

[54] Z. Da, J. Engelberg, and P. Gao, "The sum of all FEARS investor sentiment and asset prices," Review of Financial Studies, vol. 28, no. 1, pp. 1-32, 2014.

[55] W. Zhang, P. Wang, X. Li, and D. Shen, "Twitter's daily happiness sentiment and international stock returns: evidence from 
linear and nonlinear causality tests," Journal of Behavioral and Experimental Finance, vol. 18, pp. 50-53, 2018.

[56] S. Shadkhoo and G. R. Jafari, "Multifractal detrended crosscorrelation analysis of temporal and spatial seismic data," The European Physical Journal B, vol. 72, no. 4, pp. 679683, 2009.

[57] B. Podobnik, I. Grosse, D. Horvatić, S. Ilic, P. C. Ivanov, and H. E. Stanley, "Quantifying cross-correlations using local and global detrending approaches," The European Physical Journal $B$, vol. 71, no. 2, pp. 243-250, 2009.

[58] J. R. Hendrickson and W. J. Luther, "Banning bitcoin," Journal of Economic Behavior \& Organization, vol. 141, pp. 188195, 2017.

[59] S.-P. Chen and L.-Y. He, "Multifractal spectrum analysis of nonlinear dynamical mechanisms in China's agricultural futures markets," Physica A: Statistical Mechanics and its Applications, vol. 389, no. 7, pp. 1434-1444, 2010. 


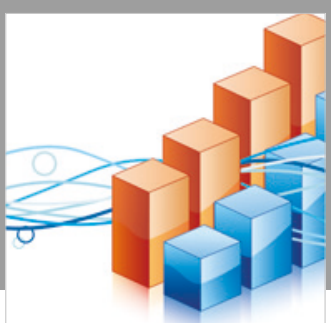

Advances in

Operations Research

\section{-n-m}
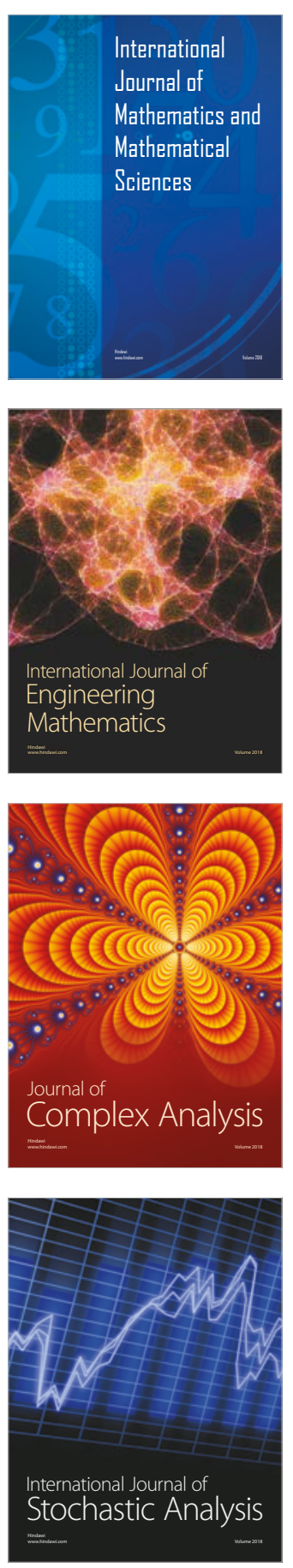
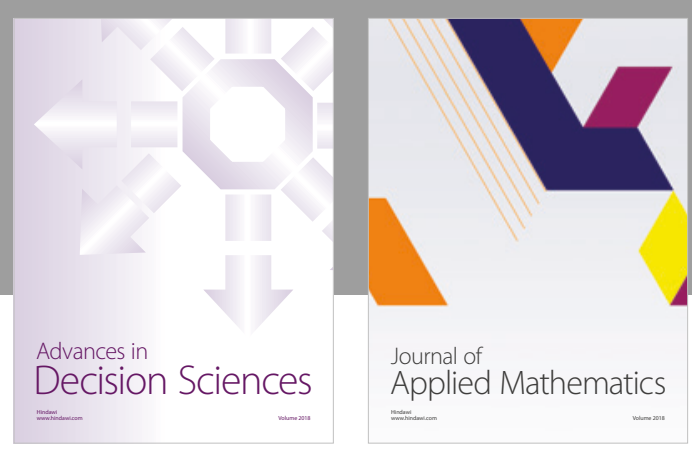

Journal of

Applied Mathematics
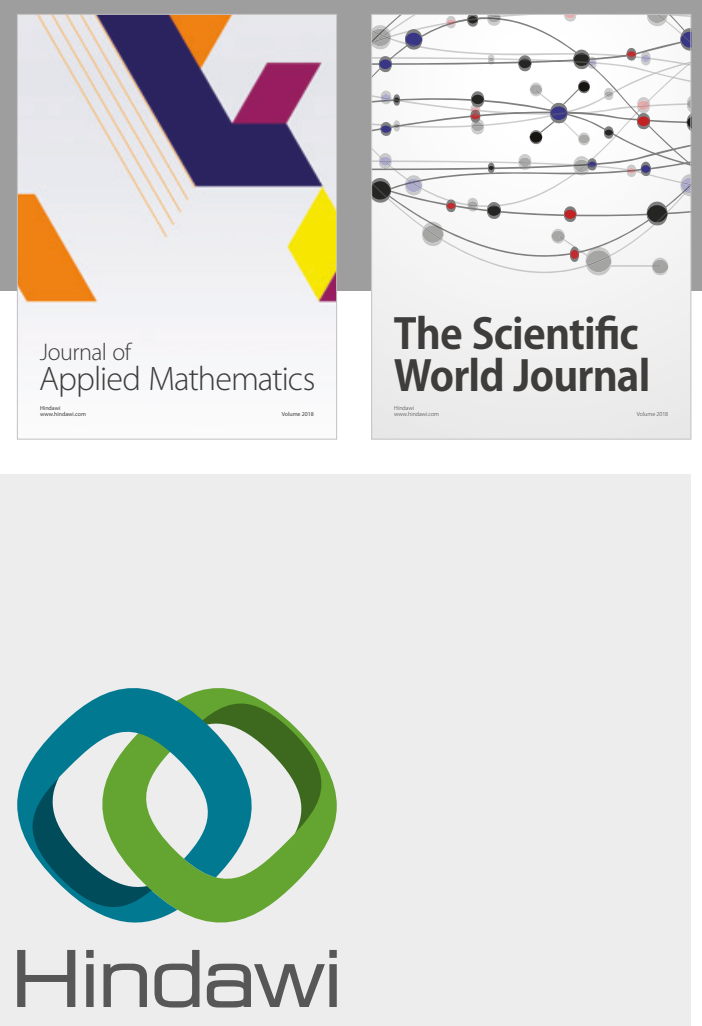

Submit your manuscripts at

www.hindawi.com

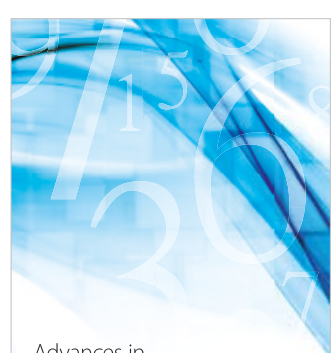

Advances in
Numerical Analysis
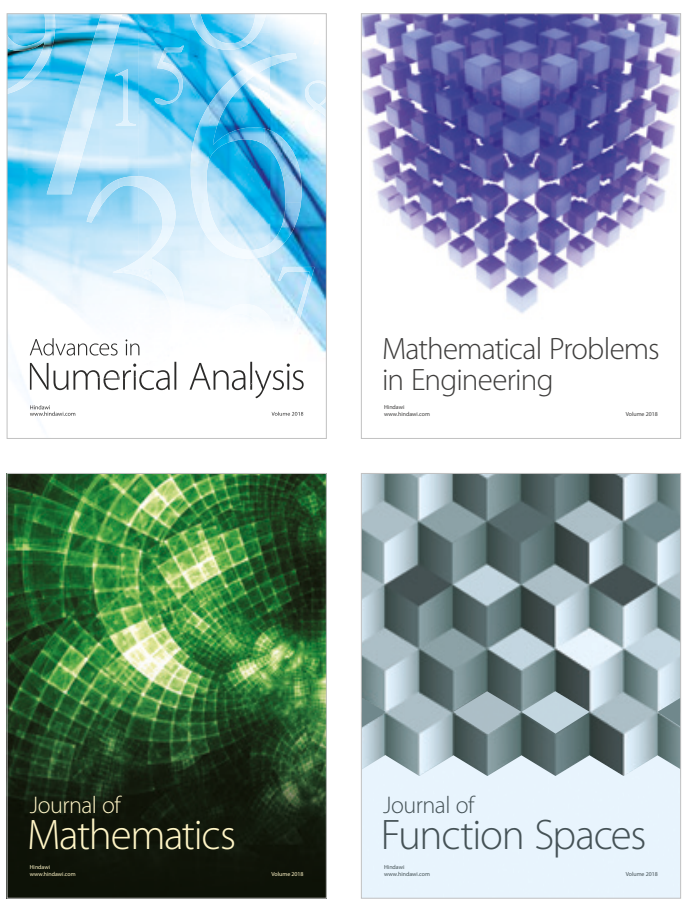

Mathematical Problems in Engineering

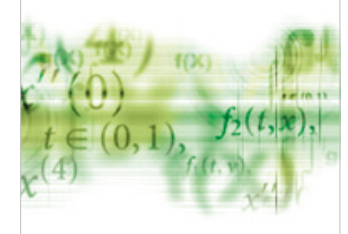

International Journal of

Differential Equations

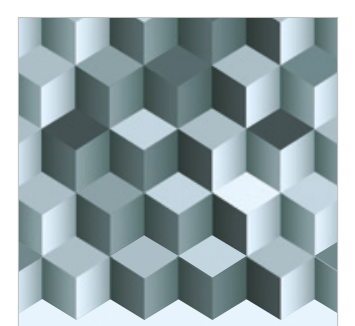

Journal of

Function Spaces
The Scientific

World Journal

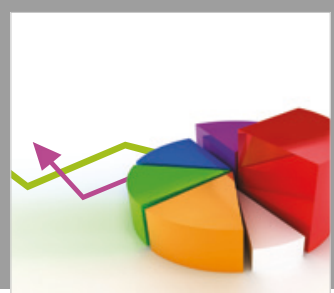

Journal of

Probability and Statistics
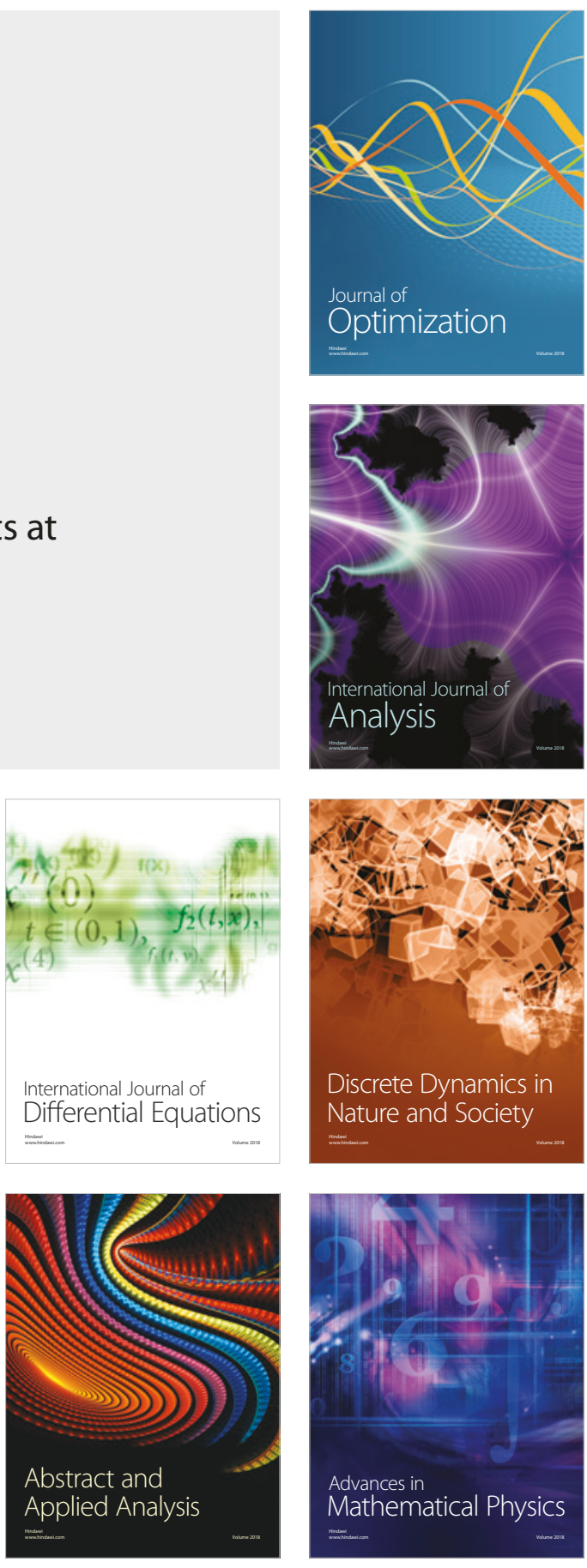